\title{
Adipic acid tolerance screening for potential adipic acid production hosts
}

\author{
Emma Karlsson ${ }^{1}$, Valeria Mapelli, ${ }^{1,2}$ and Lisbeth Olsson ${ }^{1 *}$ (D)
}

\begin{abstract}
Background: Biobased processes for the production of adipic acid are of great interest to replace the current environmentally detrimental petrochemical production route. No efficient natural producer of adipic acid has yet been identified, but several approaches for pathway engineering have been established. Research has demonstrated that the microbial production of adipic acid is possible, but the yields and titres achieved so far are inadequate for commercialisation. A plausible explanation may be intolerance to adipic acid. Therefore, in this study, selected microorganisms, including yeasts, filamentous fungi and bacteria, typically used in microbial cell factories were considered to evaluate their tolerance to adipic acid.
\end{abstract}

Results: Screening of yeasts and bacteria for tolerance to adipic acid was performed in microtitre plates, and in agar plates for A. niger in the presence of adipic acid over a broad range of concentration (0-684 mM). As the different dissociation state(s) of adipic acid may influence cells differently, cultivations were performed with at least two pH values. Yeasts and A. niger were found to tolerate substantially higher concentrations of adipic acid than bacteria, and were less affected by the undissociated form of adipic acid than bacteria. The yeast exhibiting the highest tolerance to adipic acid was Candida viswanathii, showing a reduction in maximum specific growth rate of no more than 10-15\% at the highest concentration of adipic acid tested and the tolerance was not dependent on the dissociation state of the adipic acid.

Conclusions: Tolerance to adipic acid was found to be substantially higher among yeasts and A. niger than bacteria. The explanation of the differences in adipic acid tolerance between the microorganisms investigated are likely related to fundamental differences in their physiology and metabolism. Among the yeasts investigated, C. viswanathii showed the highest tolerance and could be a potential host for a future microbial cell factory for adipic acid.

Keywords: Adipic acid, Tolerance, Screening

\section{Background}

Adipic acid is in great demand globally mainly for the production of nylon, although it is also used in the production of polyurethane, plasticizers, in controlledrelease pharmaceuticals and as a flavouring and gelling aid in food. In recent years, biobased processes for the production of adipic acid have attracted considerable interest, as a sustainable alternative to the current, environmentally detrimental production process, which is based on petrochemical sources and chemical conversion

\footnotetext{
*Correspondence: Lisbeth.Olsson@chalmers.se

1 Department of Biology and Biological Engineering, Division of Industrial Biotechnology, Chalmers University of Technology, Gothenburg, Sweden Full list of author information is available at the end of the article
}

[1-10]. In biobased processes, renewable raw materials can be converted into adipic acid with the aid of microorganisms. Microorganisms such as bacteria, yeasts, and filamentous fungi have long been used for the commercial production of various compounds with diverse applications, either by taking advantage of their natural metabolic properties, or by using genetic engineering to modify their metabolic routes to produce compounds of interest. The most common workhorses in microbial cell factories are the yeast Saccharomyces cerevisiae [11], the bacteria Escherichia coli and Corynebacterium glutamicum [12], and the filamentous fungus Aspergillus niger [13]. All these microorganisms are potential hosts for industrial adipic acid production. However, to achieve 
economic feasibility, the microorganisms should tolerate high titres of the acid, i.e., in the range $50-100 \mathrm{~g} \mathrm{~L}^{-1}$ $[14,15]$. In addition, the microorganism should also preferably tolerate low $\mathrm{pH}$, as the overall cost of processing at low $\mathrm{pH}$ is reduced, due to the lower amount of base required, and less complex downstream purification [16].

The dicarboxylic adipic acid may be present in three different forms depending on the $\mathrm{pH}$ of the environment and the $\mathrm{p} K_{\mathrm{A}}$ values of the two carboxylic groups, namely undissociated; in which both carboxylic groups are protonated, semi-dissociated; in which only one of the two carboxylic groups is protonated, and dissociated; in which neither of the carboxylic groups is protonated (Table 1). The undissociated form of an acid can enter the cell via passive diffusion over the plasma membrane [17]. Once in the cytosol, the carboxylic groups become deprotonated due to the almost neutral $\mathrm{pH}$ in the cytosol, causing acid stress in the cell. The equilibrium between the three forms of adipic acid shifts towards undissociated as the environmental $\mathrm{pH}$ decreases (Table 1), and cells will thus experience higher stress with decreasing $\mathrm{pH}[18,19]$ due to increased diffusion of undissociated adipic acid into the cell at a given total concentration of adipic acid. Although low $\mathrm{pH}$ is beneficial for downstream processing, this will probably increase the diffusion of undissociated adipic acid into the cell, causing increasing acid stress. Therefore, the $\mathrm{pH}$ of the process must be set so as to achieve a compromise between the requirements of downstream processing and stress to the cell. Cell stress may have several effects on cell physiology that could result in lower yield and/or productivity.

It has been demonstrated that the microbial production of adipic acid is possible [1-7, 20], but the yields and titres are too low for commercialisation. The reason for this could be linked to the specific metabolic

Table 1 Distribution of the forms of adipic acid at different pH values

\begin{tabular}{|c|c|c|c|c|c|}
\hline \multirow[t]{2}{*}{ Form } & \multirow[t]{2}{*}{ Structure } & \multicolumn{4}{|c|}{ Amount (\%) } \\
\hline & & $\mathrm{pH} 4$ & $\mathrm{pH} 5$ & $\mathrm{pH} 6$ & $\mathrm{pH} 7$ \\
\hline Undissociated & & 70.7 & 15.2 & 0.5 & 0.0 \\
\hline Semi-dissociated & & 28.2 & 60.6 & 20.0 & 2.5 \\
\hline Dissociated & & 1.1 & 24.1 & 79.5 & 97.5 \\
\hline
\end{tabular}

a Amounts of the three forms of adipic acid was calculated using the Henderson-Hasselbalch equation: $\mathrm{pH}=\mathrm{pKa}+\log 10\left(\left[\mathrm{~A}^{-}\right] /[\mathrm{HA}]\right)$. The $\mathrm{pKa}$ values, $\mathrm{pKa}_{1}=4.4$ and $\mathrm{pKa}_{2}=5.4$, are from Pubchem pathway employed. However, the low yields and titres of microbially produced adipic acid so far could be due to acid stress and poor cellular tolerance to adipic acid itself. Product toxicity has been identified as one of the primary challenges in developing a bioprocess for organic acid production [15]. However, to the best of our knowledge, tolerance to adipic acid has not previously been addressed. Therefore, the aim of this study was to investigate which microorganism(s) have the potential for use in a microbial cell factory for the production of adipic acid, based on their tolerance to adipic acid. The growth of well-known microorganisms, including the bacteria Escherichia coli and Corynebacterium glutamicum, the yeasts Saccharomyces cerevisiae, Zygosaccharomyces bailii and Candida viswanathii and the filamentous fungus Aspergillus niger, was screened in the presence of adipic acid over a broad range of concentrations $(0-684 \mathrm{mM})$. In addition, in order to investigate how/if different forms of adipic acid affect the microorganisms, cultures were performed at different environmental $\mathrm{pH}$ values.

\section{Methods}

\section{Strains and cultivation media}

Well-known microorganisms, were included in this study: the bacteria Escherichia coli K12 MG1655, Corynebacterium glutamicum [a wild-type strain (DSM 20300) and a lysine overproducing strain (ZW04)], the yeasts Saccharomyces cerevisiae [a lab strain (CEN.PK 113-7D) and an industrial strain (Ethanol Red)], Zygosaccharomyces bailii CBS 7555 and Candida viswanathii NCYC 997, and the filamentous fungi Aspergillus niger ATCC 1015 (see Table 2).

Yeasts were cultivated in minimal medium $\left[20 \mathrm{~g} \mathrm{~L}^{-1}\right.$ glucose, $5 \mathrm{~g} \mathrm{~L}^{-1}\left(\mathrm{NH}_{4}\right)_{2} \mathrm{SO}_{4}, 3 \mathrm{~g} \mathrm{~L}^{-1} \mathrm{KH}_{2} \mathrm{PO}_{4}, 1 \mathrm{~g} \mathrm{~L}^{-1}$ $\mathrm{MgSO}_{4} \cdot 7 \mathrm{H}_{2} \mathrm{O}, 1 \mathrm{~mL} \mathrm{~L}{ }^{-1}$ vitamin solution, $1 \mathrm{~mL} \mathrm{~L}^{-1}$ trace element solution]. Vitamin solution and trace element solution were prepared as previously described [27]. Potassium hydrogen phthalate buffer, $100 \mathrm{mM}$, was used to maintain the cultures at the desired $\mathrm{pH}$. For the

\section{Table 2 Strains used in the present study}

\begin{tabular}{lll}
\hline Species & Strain & References \\
\hline Escherichia coli & K12 MG1655 & {$[21]$} \\
Corynebacterium glutamicum & DSM 20300 (ATCC 13032) & {$[22]$} \\
Corynebacterium glutamicum & ZW04 & {$[23]$} \\
Saccharomyces cerevisiae & CEN.PK 113-7D & {$[24]$} \\
Saccharomyces cerevisiae & Ethanol Red & \\
Zygosaccharomyces bailii & CBS 7555 & \\
Candida viswanathii & NCYC 997 (ATCC 20336) & {$[25]$} \\
Aspergillus niger & ATCC 1015 & {$[26]$} \\
\hline
\end{tabular}


first and second pre-cultures $\mathrm{pH} 5.5$ was used whereas the $\mathrm{pH}$ in the microplate was either $\mathrm{pH} 5$ or $\mathrm{pH}$. The Corynebacterium glutamicum strains were cultured in media reported in- and modified from [28]; specifically a complex medium $\left(10 \mathrm{~g} \mathrm{~L}^{-1}\right.$ tryptone, $5 \mathrm{~g} \mathrm{~L}^{-1}$ beef extract, $5 \mathrm{~g} \mathrm{~L}^{-1}$ yeast extract, $2.5 \mathrm{~g} \mathrm{~L}^{-1} \mathrm{NaCl}, 10 \mathrm{~g} \mathrm{~L}^{-1}$ glucose and $5 \mathrm{~g} \mathrm{~L}^{-1}$ urea) or a minimal medium $(10 \mathrm{~g}$ $\mathrm{L}^{-1}$ glucose, $1 \mathrm{~g} \mathrm{~L}^{-1} \mathrm{NaCl}, 0.055 \mathrm{~g} \mathrm{~L}^{-1} \mathrm{CaCl}_{2} \cdot 2 \mathrm{H}_{2} \mathrm{O}$, $0.2 \mathrm{~g} \mathrm{~L}^{-1} \mathrm{MgSO}_{4} \cdot 7 \mathrm{H}_{2} \mathrm{O}, 15 \mathrm{~g} \mathrm{~L}^{-1}\left(\mathrm{NH}_{4}\right)_{2} \mathrm{SO}_{4}, 0.02 \mathrm{~g}$ $\mathrm{L}^{-1} \mathrm{FeSO}_{4} \cdot 7 \mathrm{H}_{2} \mathrm{O}, 0.0005 \mathrm{~g} \mathrm{~L}^{-1}$ biotin, $0.001 \mathrm{~g} \mathrm{~L}^{-1}$ thiamine hydrochloride, $0.03 \mathrm{~g} \mathrm{~L}^{-1}$ 3,4-dihydroxybenzoic acid, $10 \mathrm{~mL} \mathrm{~L}^{-1}$ of a $100 \times$ trace element solution [29]). Potassium phosphate $(100 \mathrm{mM})$, was used to buffer the medium at the desired $\mathrm{pH}$. For the first and second preculture $\mathrm{pH} 7$ was used whereas the $\mathrm{pH}$ in the microplate was either $\mathrm{pH} 7$ or $\mathrm{pH}$ 6. Escherichia coli $\mathrm{K} 12$ was cultured in either LB medium or a modified M9 medium (4 g L $\mathrm{g}^{-1}$ glucose, $0.241 \mathrm{~g} \mathrm{~L}^{-1} \mathrm{MgSO}_{4}, 0.011 \mathrm{~g} \mathrm{~L}^{-1} \mathrm{CaCl}_{2}$, $1 \mathrm{~g} \mathrm{~L}^{-1} \mathrm{NH}_{4} \mathrm{Cl}, 0.5 \mathrm{~g} \mathrm{~L}^{-1} \mathrm{NaCl}$ ). Potassium phosphate $(100 \mathrm{mM})$, was used to buffer the culture medium at the desired $\mathrm{pH}$. For the first and second pre-culture $\mathrm{pH} 7$ was used whereas the $\mathrm{pH}$ in the microplate was either $\mathrm{pH} 7$ or $\mathrm{pH}$ 6. Aspergillus niger was grown on agar plates containing minimal medium prepared according to [30] and $10 \mathrm{~g} \mathrm{~L}^{-1}$ glucose and $1.5-2 \%(w / v)$ agar. The $\mathrm{pH}$ of the minimal medium with agar was adjusted to desired $\mathrm{pH}$ $(\mathrm{pH} 4, \mathrm{pH} 5$ or $\mathrm{pH}$ 6) with addition of $\mathrm{HCl}$ or $\mathrm{NaOH}$. To evaluate if addition of buffer would be needed in the solid media to prevent acidification during $A$. niger growth and organic acid production, $\mathrm{pH}$ indicators were added to the media; bromophenol blue ( $\mathrm{pH} 4)$ and methyl red $(\mathrm{pH}$ 5 and $\mathrm{pH} 6)$ with final concentrations of $0.01 \%(w / v)$ or $0.005 \%(w / v)$. No detectable change in the $\mathrm{pH}$ of the solid medium was observed after 11 days of growth evaluation of $A$. niger on plates in the presence of the $\mathrm{pH}$ indicator bromophenol blue (data not shown). Since the growth of A. niger did not affect the $\mathrm{pH}$ of the agar-based medium, it was assumed that the dissociation state of adipic acid was stable over time.

\section{Medium supplements}

Stock solutions of adipic acid were prepared and adjusted to the desired $\mathrm{pH}$ at $30^{\circ} \mathrm{C}$, using $\mathrm{NaOH}$ for stocks used for $A$. niger and $\mathrm{KOH}$ for stocks used in the microplate. For osmotic control cultivations $\mathrm{KCl}$ was added to the medium at concentrations giving the same osmolality as the adipic acid supplemented media. The osmolality of the $\mathrm{KCl}$ and adipic acid stock solutions was determined from the mean of three or four measurements and confirmed to have the same osmolality using a Fiske Microosmometer, model 210. For A. niger the osmotic control cultivations were not evaluated since growth on the surface of the agar plate was considered not to be affected by the different medium osmolality. All the stock solutions used were sterile filtered through a $0.2 \mu \mathrm{m}$ aPES membrane (Thermo Fisher Scientific, Waltham, MA, USA). Adipic acid concentrations used for yeast and bacteria cultivations were: $0,6,12,24,48,96,192,384$ and $650 \mathrm{mM}$. Yeast cultures were buffered at $\mathrm{pH} 5$ and $\mathrm{pH} 6$; while bacteria cultures were buffered at $\mathrm{pH} 6$ and $\mathrm{pH} 7$. Adipic acid concentrations used in A. niger cultures on agar plates were: $0,68,171,342,513$ and $684 \mathrm{mM}$ at $\mathrm{pH}$ 6 . The highest adipic acid concentration used for $\mathrm{pH} 5$ was $513 \mathrm{mM}$, due to insolubility of $684 \mathrm{mM}$ adipic acid at $\mathrm{pH}$ 5. The adipic acid concentrations in $\mathrm{pH} 4$ medium were: $0,34,68,103$ and $137 \mathrm{mM}$.

\section{Yeast and bacterial inocula}

The first pre-culture was prepared by inoculating a single colony in $10 \mathrm{~mL}$ of medium in a $100 \mathrm{~mL}$ Erlenmeyer shake flask (E-flask) and grown overnight. The first preculture was used as the inoculum for the second pre-culture in $25 \mathrm{~mL}$ medium in a $250 \mathrm{~mL}$ E-flask with initial optical density $\left(\mathrm{OD}_{600}\right)$. Exponentially growing cells were harvested by centrifugation $(3000 \times g, 3 \mathrm{~min}$, room temperature). The supernatant was discarded and the cell pellet was re-suspended in fresh medium; the same medium as used in the following microplate cultivation. This culture was used as the inoculum for the microplate, inoculated at initial $\mathrm{OD}_{600}$ of 0.2 . The media and growth conditions for each microorganism are summarized in Table 3.

\section{Evaluation of adipic acid tolerance in microtiter plates cultures}

The cell growth kinetics of yeasts and bacteria was monitored in $145 \mu \mathrm{L}$ aerobic microscale cultures at $30^{\circ} \mathrm{C}$ using Bioscreen C MBR equipment (Oy Growth Curves Ab Ltd, Finland). For each set of experimental conditions a minimum of 5 replicates were used. The cell cultures were shaken continuously at the settings "high amplitude" and "fast speed" and stopped $5 \mathrm{~s}$ prior each optical reading. The cell density was measured optically every 15-20 min using a wideband $450-580 \mathrm{~nm}$ wavelength filter. The cell density values given by the Bioscreen were converted to equivalent $\mathrm{OD}_{600}$ using Eq. (1).

$$
O D_{600}=\frac{O D_{\text {bioscreen }}}{\text { Pathlength }(\mathrm{cm}) \times 1.32}
$$

The non-linear correlation between optical density and cell density at high cell densities was corrected using Eq. (2) [31].

$$
\begin{aligned}
O D_{\text {corrected }}= & O D_{\text {observed }}+0.449 \times O D_{\text {observed }}^{2} \\
& +0.191 \times O D_{\text {observed }}^{3}
\end{aligned}
$$


Table 3 Media and growth conditions for yeasts and bacteria used in this study

\begin{tabular}{|c|c|c|c|c|c|}
\hline \multirow[t]{2}{*}{ Microorganism } & \multicolumn{3}{|l|}{ Medium } & \multicolumn{2}{|c|}{ Growth conditions E-flask } \\
\hline & 1st pre-culture & 2nd pre-culture & Microplate & Temperature $\left({ }^{\circ} \mathrm{C}\right)$ & Shaking (rpm) \\
\hline E. coli & LB medium ( $\mathrm{pH} 7$ ) & Modified M9 medium ( $\mathrm{pH}$ 7) & Modified M9 medium ( $\mathrm{pH} 6$ or 7 ) & 37 & 200 \\
\hline C. clutamicum & Complex medium (pH 7) & Minimal medium ( $\mathrm{pH} 7$ ) & Minimal medium ( $\mathrm{pH} 6$ or 7) & 30 & 200 \\
\hline Yeasts & Minimal medium ( $\mathrm{pH}$ 5.5) & Minimal medium ( $\mathrm{pH}$ 5) & Minimal medium ( $\mathrm{pH} 5$ or 6 ) & 30 & 180 \\
\hline
\end{tabular}

The maximum specific growth rate $\left(\mu_{\max }\right)$ was calculated, together with values of the coefficient of determination $\left(\mathrm{R}^{2}\right)$, from the steepest part of the $\ln \left(\mathrm{OD}_{\text {corrected }}\right)$ curve.

The relative $\mu_{\max }$, corrected for the effect of osmotic pressure (Rel. $\left.\mu_{\max , \text { osm.cor }}\right)$, was calculated using Eq. (3).

$$
\begin{aligned}
& \text { Rel. } \mu_{\text {max,osm.cor }} \\
& =\frac{\mu_{\text {max,control }}-\mu_{\text {max,osmotictest }}+\mu_{\text {max,adipicacid }}}{\mu_{\text {max,control }}}
\end{aligned}
$$

To test for differences between two samples, statistical analysis was performed using students $T$ test, assuming two-tailed distributions, equal variance and the accepted risk level set to $<5 \%$ (i.e. the $\mathrm{p}$ value $<0.05$ ).

\section{Spore solution preparation and growth measurements of Aspergillus niger}

Black spores from a single colony were spread on a PDA plate and incubated at $30{ }^{\circ} \mathrm{C}$ for 3 days. Spores were harvested in $5 \mathrm{~mL} 0.02 \%(\mathrm{v} / \mathrm{v})$ Tween solution, $\mathrm{pH}$ 6.9. The concentration of spores was determined with a Neubauer improved haemocytometer with $0.100 \mathrm{~mm}$ depth. For growth measurements, $2 \mu \mathrm{L}$ of spore solution containing 500 spores $\mu \mathrm{L}^{-1}$ were added in triplicate to each plate. The $\mathrm{pH}$ of the plates were either $\mathrm{pH} 4, \mathrm{pH} 5$ or $\mathrm{pH}$ 6. All plates were incubated in $30{ }^{\circ} \mathrm{C}$. The growth of $A$. niger was measured every $24 \mathrm{~h}$ as the diameter $(\mathrm{mm})$ of the mycelium edges using a ruler.

\section{Estimation of the adipic acid concentration causing a certain reduction in $\mu_{\max }$}

Graphs of relative $\mu_{\text {max,osm.cor }}$ were plotted as a function of adipic acid concentration, and linear regression was performed, assuming a linear relationship. For adipic acid concentrations where no growth was observed, zero growth was defined from that concentration and above, assuming a linear trend. From these graphs, the adipic acid concentration causing a certain reduction in $\mu_{\max }$ was estimated, facilitating comparison of the tolerance of the microorganisms to adipic acid.

\section{Evaluation of growth kinetics during respiratory growth phase}

In the present study, when a second growth phase was observed following a diauxic shift and could be referred to growth under respiratory metabolism, the fold change in OD for this phase was calculated. A fold change $<1$, i.e., less than a doubling in $\mathrm{OD}$, was not considered as real growth and no further analysis was performed. Throughout this paper, unless otherwise stated, when talking about growth it means growth with a fold change greater or equal to 1 . During the time of the diauxic shift, no growth occurs and a lag phase may be observed. In this study the lag phase was defined and calculated as the time between the last time point included in the calculation of $\mu_{\max }$ during respiro-fermentation and the first time point included in the calculation of $\mu_{\max }$ during respiration.

\section{Results}

The tolerance to adipic acid was evaluated for selected microorganisms including yeasts, bacteria and filamentous fungi. Yeasts and bacteria were grown in microscale $(145 \mu \mathrm{L})$ cultures and the filamentous fungus Aspergillus niger on agar plates, all in the presence of different concentrations of adipic acid, ranging from $0 \mathrm{mM}$ to $684 \mathrm{mM}$. Cultures were grown at the $\mathrm{pH}$ optimal for each microorganism, and at least one additional $\mathrm{pH}$ value to reveal any possible effects of the dissociation state of adipic acid on the tolerance of the microorganism.

\section{Comparison of the effects caused by adipic acid and osmotic pressure}

A general trend was observed of a decrease in $\mu_{\max }$ upon increasing the adipic acid concentration. The decrease in the specific growth rate was greater for cells grown in the presence of adipic acid than in those grown under the equivalent osmotic pressure caused by the addition of $\mathrm{KCl}$.

Representative growth curves for CEN.PK 113.7D cells cultivated in adipic acid and KCL (osmotic controls) both at pH 5 are shown in Fig. 2. Growth curves for the other microorganisms are reported in the Additional file 1.

\section{Effect of adipic acid on bacteria}

Three bacterial strains were included in this study: two strains of Corynebacterium glutamicum; the wild type DSM 20300 (ATCC 13032) and the genetically modified strain ZW04 deriving from DSM 20300 able to 

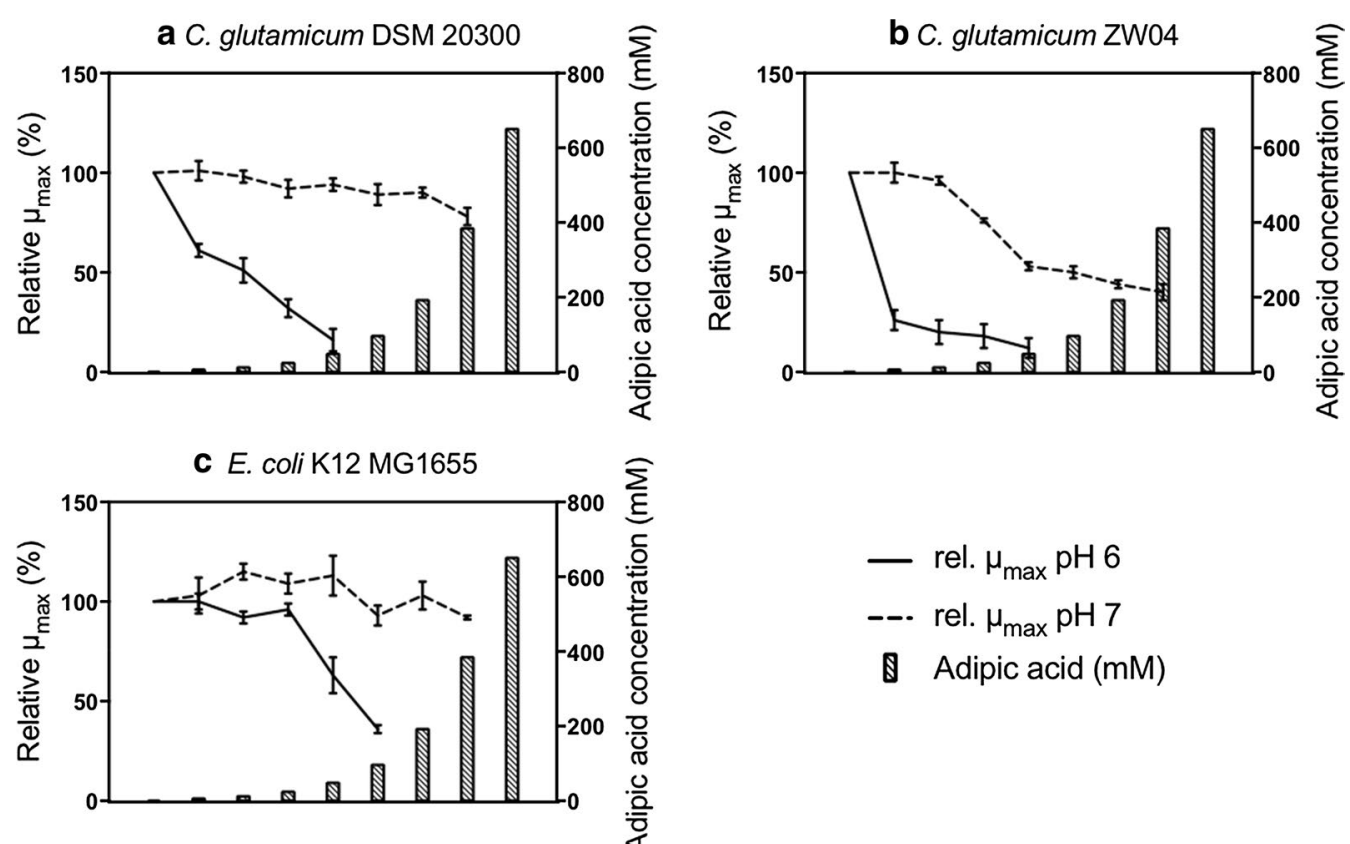

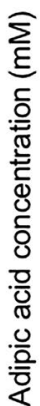

Fig. 1 Effect of adipic acid on $\mu_{\max }$ of C. glutamicum DSM 20300 (a), C. glutamicum ZW04 (b) and E. coli K12 MG1655 (c). The results are expressed as relative $\mu_{\max }$ corrected for the effect of osmotic pressure, to the $\mu_{\max }$ of cells grown without adipic acid. The results are given as the mean \pm standard deviation from five replicates. The concentrations of adipic acid are: 0, 6, 12, 24, 48, 96, 192, 384 and $650 \mathrm{mM}$

over-produce L-lysine [23], and the Escherichia coli strain K12 MG1655. All bacteria were cultivated at their optimal pH, that is $\mathrm{pH} 7$, and also at $\mathrm{pH} 6$.

\section{Corynebacterium glutamicum}

Effect of adipic acid on the growth of C. glutamicum DSM 20300 at pH 7 C. glutamicum DSM 20300 was able to grow in the presence of all the adipic acid concentrations used, except $650 \mathrm{mM}$, at which growth was completely inhibited (Additional file 1: Fig. S1). There was a trend towards a slight decrease in $\mu_{\max }$ with increasing adipic acid concentration, reaching a maximum of $22 \%( \pm 4 \%)$ reduction in the presence of $384 \mathrm{mM}$ adipic acid (Fig. 1a).

Effect of pH on C. glutamicum DSM 20300 grown in the presence of adipic acid When the $\mathrm{pH}$ was decreased from 7 to 6, the cells lost their ability to grow at concentrations of adipic acid between $48 \mathrm{mM}$ and $96 \mathrm{mM}$. Apart from tolerating lower titres of adipic acid when the $\mathrm{pH}$ was reduced, $\mu_{\max }$ was greatly affected showing a clear decrease with increasing concentration of adipic acid. The maximum specific growth rate was reduced by $39 \%( \pm 3 \%)$ already at $6 \mathrm{mM}$ adipic acid, and at $48 \mathrm{mM}$ it was reduced by $84 \%$ ( $\pm 6 \%$ ) (Fig. 1a). The final OD was also greatly affected when the $\mathrm{pH}$ was lowered to $\mathrm{pH} 6$, and the final OD decreased with increasing adipic acid concentration, which was not caused by the osmotic pressure (Additional file 1: Fig. S1). At $48 \mathrm{mM}$ adipic acid, the final OD was reduced by $59 \%( \pm 1 \%)$ compared to the control with no adipic acid. The reduction in the final OD with increasing adipic acid concentration was negligible for cells grown at $\mathrm{pH} 7$.

Effect of adipic acid on the growth of C. glutamicum ZW04 at pH 7 C. glutamicum ZW04 was able to grow at all concentrations of adipic acid tested except $650 \mathrm{mM}$, where no growth was observed (Additional file 1: Fig. S2). A considerable decrease in $\mu_{\max }$ was observed between $12 \mathrm{mM}$ and $48 \mathrm{mM}$, from $4 \%( \pm 2 \%)$ to $47 \%( \pm 2 \%)$. The maximum specific growth rate was further reduced with increasing adipic acid concentration, but the decline was not as large. The greatest reduction in $\mu_{\max }, 60 \%( \pm 4 \%)$ was seen at $384 \mathrm{mM}$ adipic acid (Fig. 1b). The final OD decreased with increasing adipic acid concentration, by $54 \%( \pm 1 \%)$ at $384 \mathrm{mM}$ adipic acid compared with the control with no adipic acid. The reduction in final OD in the osmotic controls was negligible (Additional file 1: Fig. S2).

Effect of $p H$ on C. glutamicum ZWO4 grown in the presence of adipic acid When decreasing the $\mathrm{pH}$ from 7 to 6 , the cells lost their ability to grow at concentrations of adipic acid between $48 \mathrm{mM}$ and $96 \mathrm{mM}$. Apart from tolerating less high titres of adipic acid when the $\mathrm{pH}$ was reduced, $\mu_{\max }$ was greatly affected: at $6 \mathrm{mM}$ adipic acid 
$\mu_{\max }$ was reduced by $74 \%( \pm 5 \%)$, while at $48 \mathrm{mM}$ adipic acid $\mu_{\max }$ was reduced by $88 \%$ ( $\pm 5 \%$ ) (Fig. 1 b). The final OD also decreased with increasing adipic acid concentration, and at $48 \mathrm{mM}$ final OD was reduced by $72 \%( \pm 1 \%)$ compared to control. In the osmotic control no reduction in final OD was evident up to osmotic pressures corresponding to $48 \mathrm{mM}$ adipic acid. At higher osmotic pressures, a decrease in final OD was observed with increasing osmotic pressure (Additional file 1: Fig. S2).

\section{Escherichia coli}

Effect of adipic acid on the growth of E. coli K12 MG1655 at $p H 7$ E. coli $\mathrm{K} 12 \mathrm{MG} 1655$ was able to grow at all concentrations of adipic acid, except $650 \mathrm{mM}$. It is interesting to note that this strain was the only one among all yeasts and bacteria investigated that could not grow at an osmotic pressure equivalent to $650 \mathrm{mM}$ of adipic acid. However, at $384 \mathrm{mM}$ adipic acid $\mu_{\max }$ was significantly more affected than in the osmotic control, showing that adipic acid affected growth rate more than osmotic pressure. There was no clear trend in $\mu_{\max }$ as a function of increasing adipic acid, and in fact a slight increase in $\mu_{\max }$ was observed between $12 \mathrm{mM}$ and $48 \mathrm{mM}$ of adipic acid. In cultures with $384 \mathrm{mM}$ adipic acid, $\mu_{\max }$ was only reduced by $8 \%( \pm 1 \%)$ (Fig. 1c). It should also be noted that there were indications of a second growth phase up to $48 \mathrm{mM}$ adipic acid, but the fold change in OD was well below 1 (Additional file 1: Fig. S3).

Effect of $p H$ on E. coli K12 MG1655 grown in the presence of adipic acid At $\mathrm{pH}$ 6, E. coli growth was completely inhibited at adipic acid concentrations between $96 \mathrm{mM}$ and $192 \mathrm{mM}$. Apart from tolerating lower concentrations of adipic acid when the $\mathrm{pH}$ was reduced, $\mu_{\max }$ was greatly affected between $24 \mathrm{mM}$ and $96 \mathrm{mM}$ adipic acid, being only $4 \%( \pm 3 \%)$ at $24 \mathrm{mM}$ but $64 \%( \pm 2 \%)$ at $96 \mathrm{mM}$ (Fig. 1c). A second growth phase was only observed for the control with no adipic acid. The final OD was greatly affected by increasing adipic acid concentration and at $96 \mathrm{mM}$ adipic acid, the final maximum OD was reduced with $64 \%( \pm 3 \%)$ compared to the control with no adipic acid after the first growth phase. The reduction in final $\mathrm{OD}$ in the osmotic controls, corresponding to adipic acid concentration of $96 \mathrm{mM}$, was negligible (Additional file 1: Fig. S3).

Comparison of the tolerance of bacteria to adipic acid At $\mathrm{pH} 7$, all bacteria were able to grow at $384 \mathrm{mM}$ adipic acid. At $384 \mathrm{mM}$ adipic acid, E. coli showed the least reduction in $\mu_{\max }$, followed by C. glutamicum DSM 20300. The lysine-producing strain C. glutamicum ZW04 showed the least tolerance to adipic acid. When the $\mathrm{pH}$ was decreased to $\mathrm{pH} \mathrm{6}$, the tolerance of all investigated bacteria species/ strains to adipic acid decreased. Even at lower concentrations of adipic acid, $\mu_{\max }$ was much more affected at $\mathrm{pH} 6$ than at $\mathrm{pH}$ 7. Overall, E. coli K12 MG1655 was the bacterial strain that tolerated adipic acid best, whereas the lysine-producing strain C. glutamicum ZW04 was the least tolerant to adipic acid. At $\mathrm{pH}$ 6, the C. glutamicum strain ZW04 showed the same level of reduction in $\mu_{\max }$ as the DSM 20300 strain at $48 \mathrm{mM}$ adipic acid, but since the reduction in $\mu_{\max }$ at lower adipic acid concentration, was greater for ZW04 strain than for the wild type (Fig. 1a, b) it can be deduced that the tolerance of C. glutamicum ZW04 to adipic acid is lower than that of the wild type strain, also at $\mathrm{pH}$ 6. In Table 4 the reduction in $\mu_{\max }$ at the highest concentrations of adipic acid allowing growth is summarized for all bacteria at both pH 6 and pH 7 .

Effect of adipic acid on yeasts Three yeast species were investigated: two strains of Saccharomyces cerevisiae (the laboratory strain CEN.PK 113-7D and the industrial strain Ethanol Red) the food spoilage yeast Zygosaccharomyces bailii CBS 7555, known to tolerate high concentrations of various acids such as acetic acid [32], and Candida viswanathii NCYC 997 (ATCC 20336), a strain known to produce lipases (triacylglycerol acyl hydrolase, EC 3.1.1.3) allowing this yeast to grow on fatty acids and alkanes as sole carbon source $[7,33]$ and of high industrial interest for the production of adipic acid [34]. All yeasts were cultivated at their optimal $\mathrm{pH}$, which is $\mathrm{pH} 5$. In addition, yeasts were also cultivated at $\mathrm{pH} 6$, yielding a lower concentration of undissociated acid compared to $\mathrm{pH} 5$.

\section{Saccharomyces cerevisiae}

Effect of adipic acid on the growth of CEN.PK 113-7D at $p H 5$ Under the first growth phase, during respirofermentation, CEN.PK 113-7D cells were able to grow in the presence of all concentrations of adipic acid tested (Fig. 2a, b). An initial lag phase was observed at the highest acid concentration. Between adipic acid concentrations of $96 \mathrm{mM}$ and $196 \mathrm{mM}, \mu_{\max }$ was significantly reduced, and continued to decrease with increasing adipic acid concentration. At a concentration of $650 \mathrm{mM}$ the reduction in $\mu_{\max }$ was $45 \%$ ( $\pm 4 \%$ ) (Fig. $2 \mathrm{c}$ ) and the final OD was $39 \%$ $( \pm 1 \%)$ lower compared to the control with no adipic acid. The reduction in the final OD was significantly greater than that caused by osmotic pressure, where the reduction in the final OD was $17 \%( \pm 1 \%)$.

After the diauxic shift, when yeast metabolism changed from respiro-fermentative to fully respiratory, growth was observed up to an adipic acid concentration of $96 \mathrm{mM}$, while respiratory growth was completely inhibited at higher acid concentrations (Fig. 2a). The inhibition in respiratory growth observed between $96 \mathrm{mM}$ and $192 \mathrm{mM}$ adipic acid was not caused by the osmotic 
Table 4 Reduction in $\mu_{\max }$ for bacteria at the highest concentration of adipic acid allowing growth

\begin{tabular}{|c|c|c|c|c|c|}
\hline \multirow[t]{2}{*}{ Species } & \multirow[t]{2}{*}{ Strains } & \multicolumn{2}{|l|}{$\mathrm{pH} 7$} & \multicolumn{2}{|l|}{ pH 6} \\
\hline & & Reduction in $\mu_{\max }(\%)$ & Adipic acid (mM) & Reduction in $\mu_{\max }(\%)$ & Adipic acid (mM) \\
\hline C. glutamicum & DSM 20300 & $22 \pm 4$ & 384 & $84 \pm 6$ & 48 \\
\hline C. glutamicum & ZW04 & $60 \pm 4$ & 384 & $88 \pm 5$ & 48 \\
\hline E. coli & K12 MG1655 & $8 \pm 1$ & 384 & $64 \pm 2$ & 96 \\
\hline
\end{tabular}

The reduction in $\mu_{\max }$ is corrected for osmotic pressure and compared to control with no adipic acid. Values given are the mean \pm standard deviation of five replicates

a Adipic acid
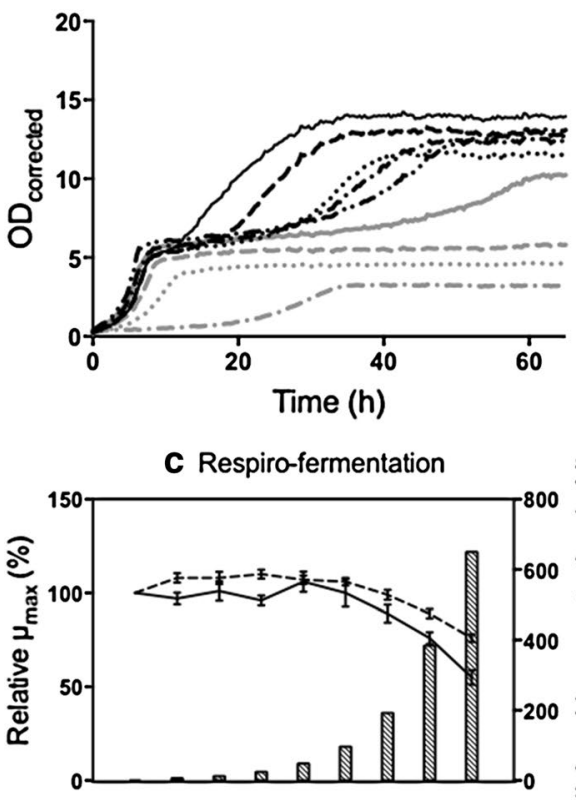

e Lag phase between growth phases

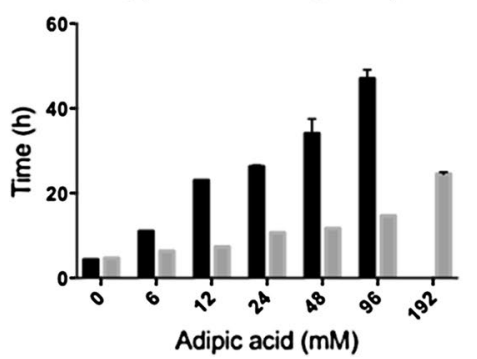

b Osmotic control

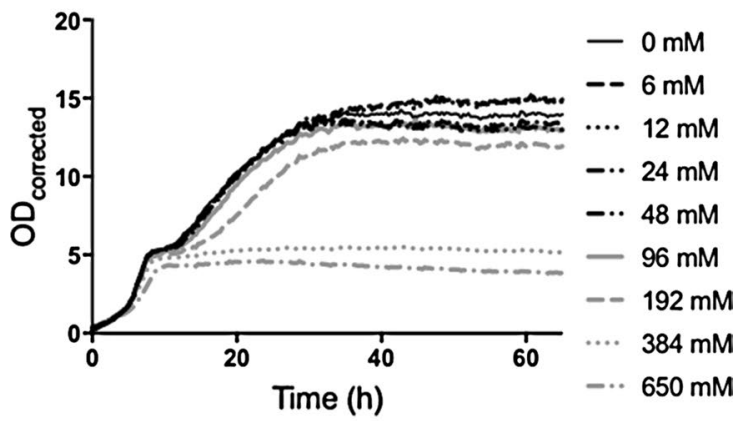

d Respiration

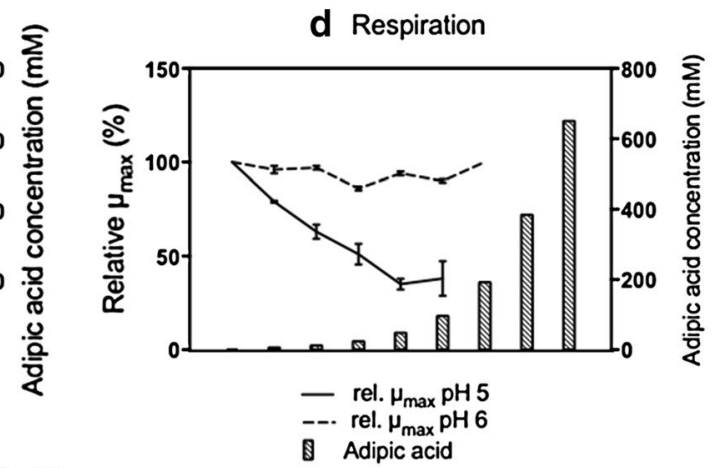

- rel. $\mu_{\max } \mathrm{pH} 5$

Adipic acid

$\mathrm{pH} 5$

pH 6

Fig. 2 Effect of adipic acid on the growth kinetics of S. cerevisiae CEN.PK 113-7D. Growth curves for cultures at pH 5 in the presence of adipic acid (a) and osmotic pressure control experiments $(\mathbf{b})$. The corresponding concentration of adipic acid is reported in the osmotic pressure experiments. Relative $\mu_{\max }$ during respiro-fermentative growth $(\mathbf{c})$ and respiratory growth $(\mathbf{d})$. The results are expressed as relative $\mu_{\text {max }}$ corrected for the effect of osmotic pressure, to the $\mu_{\max }$ of cells grown without adipic acid. The results are given as the mean \pm standard deviation from five replicates. The concentrations of adipic acid are: 0, 6, 12, 24, 48, 96, 192, 384 and 650 mM. Lag phase between the respiro-fermentative and the respiratory growth phase $(\mathbf{e})$ where the bars represent mean \pm standard deviation for five replicates

pressure, although osmotic pressure played a major role in inhibiting respiratory growth at concentrations of 384 and $650 \mathrm{mM}$. During respiratory growth, $\mu_{\max }$ decreased significantly with increasing adipic acid concentration, compared to the control. The reduction in $\mu_{\max }$ was $62 \%$
$( \pm 9 \%)$ at $96 \mathrm{mM}$ adipic acid (Fig. 2d) and the final OD was reduced by $26 \%( \pm 15 \%)$ compared to the control. The final OD of the osmotic control was not affected by applying an osmotic pressure equivalent to $96 \mathrm{mM}$ adipic acid. 
It was also observed that the lag phase between the respiro-fermentative and respiratory growth phases, increased with increasing adipic acid concentration. In the control with no adipic acid, the lag phase was $4.3 \mathrm{~h}$ while it increased to $47 \mathrm{~h}( \pm 2 \mathrm{~h})$ with $96 \mathrm{mM}$ adipic acid (Fig. 2e). This increase in time was not observed in the osmotic control measurements (data not shown).

Effect of $p H$ on CEN.PK 113-7D grown in the presence of adipic acid When the $\mathrm{pH}$ of the medium was buffered to $\mathrm{pH} 6$, the most important differences compared to $\mathrm{pH} 5$ during respiro-fermentative growth were the lack of a lag phase in the presence of $650 \mathrm{mM}$ adipic acid and a smaller decrease in $\mu_{\max }$ with increasing adipic acid concentration. At $650 \mathrm{mM}$ adipic acid, $\mu_{\max }$ was reduced by $24 \%( \pm 2 \%)$, which was significantly less than at $\mathrm{pH} 5$, where the reduction in $\mu_{\max }$ was $45 \%$ ( $\pm 4 \%$ ) (Fig. 2 c). The final OD after the first growth phase was not considerably affected by the change in $\mathrm{pH}$ (Additional file 1: Fig. S4).

During respiratory growth, no decrease in $\mu_{\max }$ was observed at pH 6 with increasing adipic acid concentration. Cells were able to grow at concentrations of adipic acid up to $192 \mathrm{mM}$, whereas at $\mathrm{pH} 5$, respiratory growth was only observed up to $96 \mathrm{mM}$ adipic acid (Fig. 2d). Furthermore, the lag phase between the respiro-fermentative and the respiratory growth phases was less affected at $\mathrm{pH} 6$ than at $\mathrm{pH} 5$ being $47 \mathrm{~h}( \pm 2 \mathrm{~h})$ with $96 \mathrm{mM}$ adipic acid at $\mathrm{pH} 5$, and $15 \mathrm{~h}$ at $\mathrm{pH} 6$ (Fig. 2e). In addition, the maximum OD was less affected at increasing adipic acid concentrations at $\mathrm{pH} 6$ than at $\mathrm{pH}$ 5. No significant effect was seen on $\mu_{\max }$ in the osmotic control measurements at pH 6 up to $192 \mathrm{mM}$ adipic acid, while at osmotic pressures corresponding to $384 \mathrm{mM}$ and $650 \mathrm{mM}$ adipic acid, osmotic stress played a considerable role, inhibiting $\mu_{\max }$ and negatively affecting the final OD reached (Additional file 1: Fig. S7).

Effect of adipic acid on the growth of Ethanol Red at $p H$ 5 During respiro-fermentation, cells of Ethanol Red were able to grow in the presence of all concentrations of adipic acid tested, except $650 \mathrm{mM}$. $\mu_{\max }$ showed a slight increase between $12 \mathrm{mM}$ and $48 \mathrm{mM}$ adipic acid, whereas at $192 \mathrm{mM}$ it decreased significantly, compared to the control with no adipic acid, and continued to decrease with increasing adipic acid concentration. At $384 \mathrm{mM}$ adipic acid, the reduction in $\mu_{\max }$ was $40 \%$ ( $\pm 5 \%$ ) (Fig. 3a) and the final OD before the diauxic shift, in relation to control, with no adipic acid was reduced by $16 \%( \pm 1 \%)$, which was not observed in the osmotic control (Additional file 1: Figs. S5, S6).

After the diauxic shift, a fold change of $O D \geq 1$ was observed up to $96 \mathrm{mM}$ adipic acid, but this was reduced to 0 at $192 \mathrm{mM}$ adipic acid when the growth of Ethanol
Red was inhibited. At $96 \mathrm{mM}$ adipic acid, there was a significant reduction $(45 \pm 15 \%)$ in $\mu_{\max }$ compared to the control with no adipic acid (Fig. 3b). The values of $\mu_{\max }$ obtained during respiration showed large error bars, possibly indicating that Ethanol Red may be less efficient than the CEN.PK 113-7D strain in respiratory metabolism. This observation could be related to the fact that Ethanol Red has been evolved and selected for its highly fermentative metabolism and high ethanol yields. The maximum OD after the second growth phase was reduced by $20 \%( \pm 12 \%)$ in the presence of $96 \mathrm{mM}$ of adipic acid, and this reduction was not due to osmotic pressure (Additional file 1: Figs. S5, S6).

The lag phase between respiro-fermentative and respiratory growth phases increased slightly with increasing adipic acid concentration. In the control experiment with no adipic acid added the lag phase was $3.8 \mathrm{~h}( \pm 0.5 \mathrm{~h})$, and increased to $8.5 \mathrm{~h}( \pm 1 \mathrm{~h})$ at $96 \mathrm{mM}$ adipic acid. This increase in lag phase was not observed in the osmotic control experiments (data not shown).

Effect of pH on Ethanol Red grown in the presence of adipic acid When the $\mathrm{pH}$ of the medium was increased from $\mathrm{pH} 5$ to $\mathrm{pH} 6$, a number of differences were observed. During respiro-fermentation, cells were able to grow at higher concentrations of adipic acid, even at the maximum concentration of $650 \mathrm{mM}$. The negative effect on $\mu_{\max }$ was milder at $\mathrm{pH} 6$ than at $\mathrm{pH} 5$ : at $650 \mathrm{mM}$ adipic acid, $\mu_{\max }$ was reduced by $21 \%( \pm 10 \%)$ at $\mathrm{pH} 6$, compared with a reduction of $40 \%( \pm 5 \%)$ at $\mathrm{pH} 5$ in the presence already at $384 \mathrm{mM}$ adipic acid (Fig. 3a).

During the respiratory phase, growth was detectable at pH 6 up to $192 \mathrm{mM}$ adipic acid, whereas it was completely inhibited at $\mathrm{pH} 5$. Although Ethanol Red cells could sustain higher concentrations of adipic acid at $\mathrm{pH}$ $6, \mu_{\max }$ was more affected than at $\mathrm{pH}$ 5. The error bars were also large at this $\mathrm{pH}$ (Fig. 3b). Furthermore, the lag phase between the respiro-fermentative and the respiratory growth phases was less affected at $\mathrm{pH} 6$ than $\mathrm{pH} 5$. Only at the highest concentration permitting growth (192 mM adipic acid) was a significant increase observed, from $4.2 \mathrm{~h}( \pm 1.2 \mathrm{~h})$ in the control with no adipic acid to $7.1 \mathrm{~h}( \pm 0.3 \mathrm{~h})$. In the osmotic control experiments no increase in the lag time was observed with increasing osmotic pressure (data not shown).

\section{Zygosaccharomyces bailii}

Effect of adipic acid on the growth of CBS 7555 at pH 5 Cells of $Z$. bailii were able to grow in the presence of all concentrations of adipic acid tested. At the highest concentration of $650 \mathrm{mM}$ a long initial lag phase was detected, which was not observed in the osmotic control experiments (Additional file 1: Fig. S7). A signifi- 


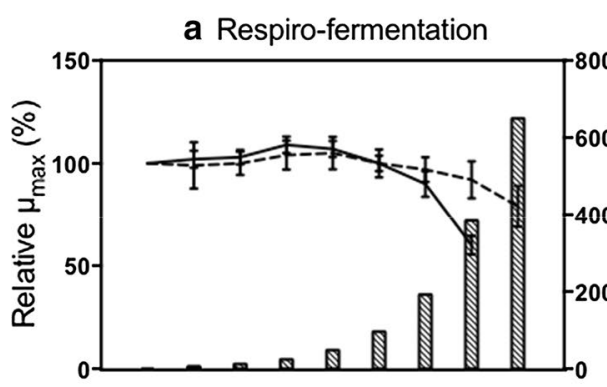

C Lag phase between growth phases

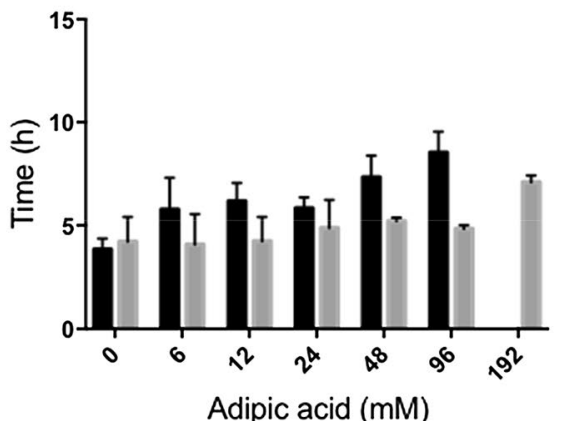

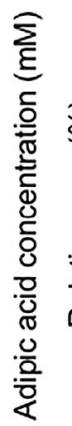

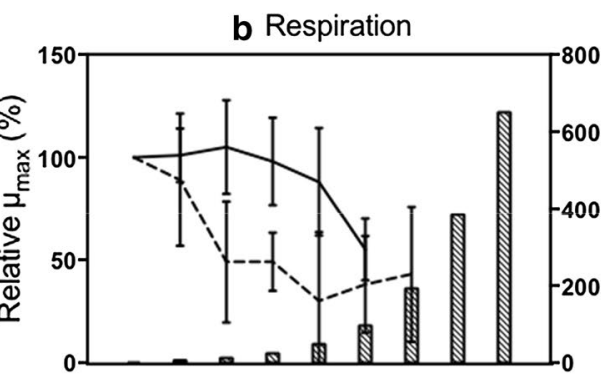

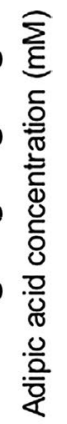

— rel. $\mu_{\max } \mathrm{pH} 5$
--. rel. $\mu_{\max } \mathrm{pH} 6$
- Adipic acid
pH 5

$\mathrm{pH} 6$

Fig. 3 Effect of adipic acid on the growth kinetics of S. cerevisiae Ethanol Red. Relative $\mu_{\max }$ during respiro-fermentative growth (a) and respiratory growth $(\mathbf{b})$. Lag phase between the respiro-fermentative and the respiratory growth phase $(\mathbf{c})$. The results in $A$ and $B$ are expressed as relative $\mu_{\max }$ corrected for the effect of osmotic pressure, to the $\mu_{\max }$ of cells grown without adipic acid. The concentrations of adipic acid are: 0, 6, 12, 24, 48, 96, 192,384 and $650 \mathrm{mM}$. All results are given as the mean \pm standard deviation from ten replicates

cant reduction in $\mu_{\max }$ was observed between adipic acid concentrations of $24 \mathrm{mM}$ and $48 \mathrm{mM}$, and this decrease continued with increasing adipic acid concentration. At the highest concentration of adipic acid, the reduction in $\mu_{\max }$ was $59 \%$ ( $\pm 3 \%$ ) (Fig. $\left.4 \mathrm{a}\right)$, and the final OD before the diauxic shift was reduced by $43 \%( \pm 7 \%)$, compared to the control with no adipic acid. Osmotic stress was not the cause of the observed growth inhibition (Additional file 1: Fig. S7).

After the diauxic shift, a fold change of only $0.7( \pm 0.1)$ was observed in the OD in the absence of adipic acid. This is due to the intrinsic metabolic features of $Z$. bailii, the respiro-fermentative metabolism of which is shifted more towards respiration than in the case of $S$. cerevisiae $[35,36]$. The lag phase between the respiro-fermentative and the respiratory growth phases was affected by both adipic acid and osmotic pressure. For cells grown in presence of adipic acid the time for the lag phase increased with increasing adipic acid concentration, whereas no obvious trend in time for the lag phase with increasing osmotic pressure could be observed (Additional file 1: Fig. S7).

Effect of pH on CBS 7555 grown in the presence of adipic acid When the $\mathrm{pH}$ of the medium was increased from pH 5 to $\mathrm{pH} \mathrm{6,} \mathrm{a} \mathrm{number} \mathrm{of} \mathrm{differences} \mathrm{were} \mathrm{observed.}$
There was no lag phase detected at $650 \mathrm{mM}$ adipic acid, and $\mu_{\max }$ decreased to a less extent than at $\mathrm{pH} 5$ with increasing adipic acid concentration. At $650 \mathrm{mM}, \mu_{\max }$ was reduced by $29 \%( \pm 2 \%)$, while at $\mathrm{pH} 5$ the reduction in the $\mu_{\max }$ was $59 \%$ ( $\pm 3 \%$ ) (Fig. 4a). The lag phase between the respiro-fermentative and the respiratory growth phases was less affected by both adipic acid and osmotic pressure (Additional file 1: Fig. S7).

\section{Candida viswanathii}

Effect of adipic acid on the growth of NCYC 997 For neither $\mathrm{pH} 5$ or $\mathrm{pH} 6$ none of the adipic acid concentrations tested completely inhibited the growth of NCYC 997, and no lag phase could be detected at any concentration of adipic acid or in the osmotic control experiments (Additional file 1: Fig. S8). A slight decrease in $\mu_{\max }$ was observed with increasing adipic acid concentration. In the presence of $650 \mathrm{mM}$ adipic acid, the $\mu_{\max }$ was reduced by $11 \%( \pm 8 \%)$ at $\mathrm{pH} 5$ and by $14 \%( \pm 4)$ at $\mathrm{pH} 6$ (Fig. $4 \mathrm{~b})$. After the diauxic shift, the OD increased by only 0.5 units, possibly suggesting that $C$. viswanathii has a primarily respiratory metabolism, as has been proposed for the closely related Candida tropicalis [37]. It should also be noted that cell shape may affect the OD values obtained with the Bioscreen [38]. It can, therefore, not be excluded that the increase in OD observed after the first growth phase was an artefact 

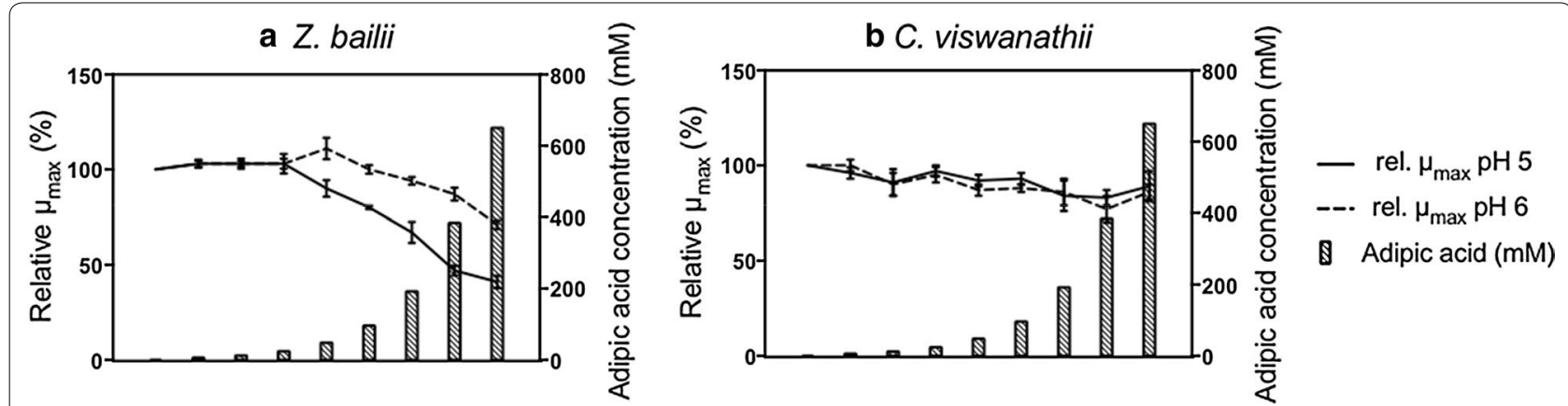

Fig. 4 Effect of adipic acid on relative $\mu_{\max }$ for $Z$. bailii $(\mathbf{a})$ and $C$. viswanathii $(\mathbf{b})$. The results are expressed as relative $\mu_{\text {max }}$ corrected for the effect of osmotic pressure, to the $\mu_{\max }$ of cells grown without adipic acid. The concentrations of adipic acid are: 0, 6, 12, 24, 48, 96, 192, 384 and 650 mM. All results are given as the mean \pm standard deviation from five replicates

resulting from a change in cell shape over time, and not due to an increase in cell mass owing to respiration. The final OD was slightly affected by adipic acid and at $650 \mathrm{mM}$ it was reduced by $24 \%( \pm 2 \%)$, which was not observed in the osmotic control experiments. The decrease in final OD was lower at $\mathrm{pH} \mathrm{6}$, and at $650 \mathrm{mM}$ adipic acid it was reduced by $12 \%$ ( $\pm 2 \%$ ) (Additional file 1: Fig. S8).

Comparison of the tolerance of yeasts to adipic acid All yeast species tested were able to grow under respiro-fermentative metabolism, or potentially full respiration as suggested for $C$. viswanathii, in the presence of adipic acid up to the maximum concentration of $650 \mathrm{mM}$, at both $\mathrm{pH}$ 5 and $\mathrm{pH} 6$, apart from Ethanol Red, which did not grow at $650 \mathrm{mM}$ adipic acid at $\mathrm{pH}$. The maximum specific growth rate of all strains were less affected by adipic acid when grown at $\mathrm{pH} 6$ compared to $\mathrm{pH} 5$, apart from $C$. viswanathii, in which no difference could be observed. Among the yeasts investigated, C. viswanathii was the yeast with the highest tolerance to adipic acid at both $\mathrm{pH}$ 5 and $\mathrm{pH} 6$ (Table 5).

Effect of adipic acid on the filamentous fungus Aspergillus niger Aspergillus niger is a natural producer of citric acid and is used for industrial-scale production of citric acid at low $\mathrm{pH}$ [13]. Its ability to produce organic acids at low $\mathrm{pH}$ makes it an interesting candidate as a host for the production of adipic acid. In the present study, the tolerance of the wild type strain of $A$. niger (ATCC 1015) to adipic acid when grown on agar plates was evaluated.

Effect of adipic acid on the growth of A. niger Growth was observed under all the conditions tested, and no significant difference in reduction of $\mu_{\max }$ was seen between the three pH values (pH 4, pH 5 and pH 6) tested (Fig. 5). Compared to the control with no adipic acid, a significant reduction
Table 5 Reduction in $\mu_{\max }$ during first growth phase of yeasts with $650 \mathrm{mM}$ adipic acid

\begin{tabular}{llll}
\hline Species & Strain & pH 5 (\%) & pH 6 (\%) \\
\hline S. cerevisiae & CEN.PK 113-7D & $45 \pm 4$ & $24 \pm 2$ \\
S. cerevisiae & Ethanol Red & n.d. & $30 \pm 4$ \\
Z. bailii & CBS 7555 & $59 \pm 3$ & $29 \pm 2$ \\
C. viswanathii & NCYC 977 & $11 \pm 8$ & $14 \pm 4$ \\
\hline
\end{tabular}

The reduction in $\mu_{\max }$ is corrected for osmotic pressure and compared to control with no adipic acid. Values given are the mean \pm standard deviation of five replicates except for Ethanol Red where ten replicates were used

a No respiro-fermentative growth could be detected at $650 \mathrm{mM}$ adipic acid at $\mathrm{pH} 5$

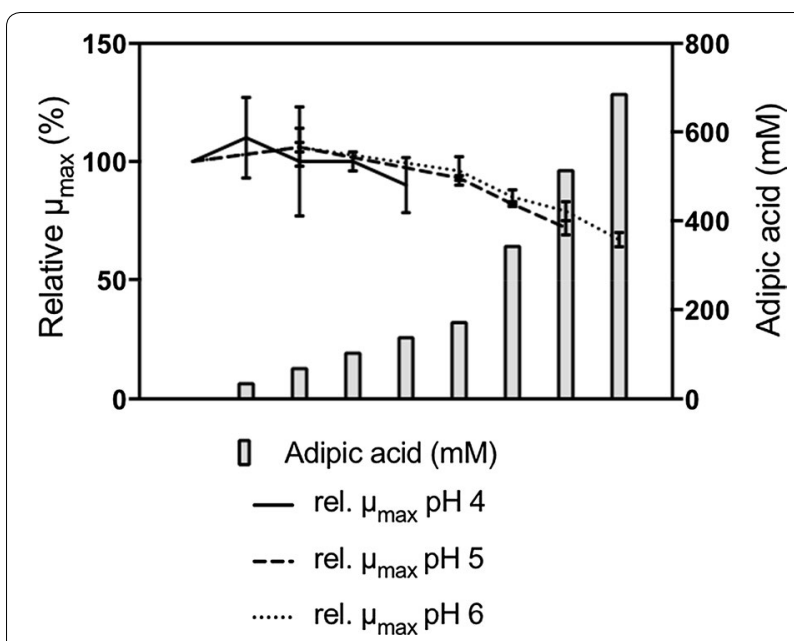

Fig. 5 Effect of adipic acid on relative $\mu_{\max }$ of $A$. niger. The results are expressed as relative $\mu_{\max }$ to the $\mu$ max of cells grown without adipic acid. The concentrations of adipic acid for $\mathrm{pH} 5$ and $\mathrm{pH} 6$ are: $0,68,171,342$ and $513 \mathrm{mM}$. For $\mathrm{pH} 6$ there is also $684 \mathrm{mM}$. For pH 4 the concentrations of adipic acid are: 0, 34, 68, 103 and $137 \mathrm{mM}$. All results are given as the mean \pm standard deviation from three to six replicates 
in $\mu_{\max }$ was seen with increasing adipic acid concentration starting at $>68 \mathrm{mM}$, at $\mathrm{pH} 5$, showing a reduction of $28 \%$ $( \pm 3 \%)$ at $513 \mathrm{mM}$. At pH 6 a slight increase in $\mu_{\max }$ was observed at $68 \mathrm{mM}$ adipic acid, followed by a significant decrease in $\mu_{\max }$ at adipic acid concentrations $>171 \mathrm{mM}$, with a reduction in $\mu_{\max }$ of $33 \%( \pm 3 \%)$ at $684 \mathrm{mM}$. At $\mathrm{pH}$ 4 , no significant difference in relative $\mu_{\max }$ was observed at any adipic acid concentration tested (Fig. 5).

Effect of adipic acid on spore formation of $A$. niger From visual inspection of the colonies it was observed that spore formation was affected by adipic acid; less dense spore formation being seen with increasing adipic acid concentration at pH 5 and pH 6 (Fig. 6). At pH 4, no clear trend could be seen (data not shown). A difference in spore formation was seen depending on the $\mathrm{pH}$, with less dense spores at $\mathrm{pH}$ 5 than at $\mathrm{pH} 6$. This is clear when comparing the plates with $513 \mathrm{mM}$ adipic acid concentration at pH 5 and 6 .

\section{Comparison of the tolerance of all the microorganisms to adipic acid}

Since the distribution between the various forms of adipic acid and hence, the amount of membrane-diffusible adipic acid, varies with $\mathrm{pH}$, the comparison of all the microorganisms investigated in this study must be made by considering cultures grown at the same $\mathrm{pH}$. All the microorganisms included in this study were able to grow in the control cultures with no adipic acid at $\mathrm{pH} 6$, and were therefore compared at this $\mathrm{pH}$.

\section{Yeasts and A. niger tolerate far higher titres of adipic acid than bacteria}

The maximum specific growth rate was reduced by $25 \%$ already at very low concentrations of adipic acid (e.g., $<10 \mathrm{mM}$ for the C. glutamicum strains and $\sim 50 \mathrm{mM}$ for E. coli). A similar reduction in $\mu_{\max }$ was not observed in any yeast species or $A$. niger until higher concentrations of adipic acid (as high as $>550 \mathrm{mM}$ ) (Fig. 7). For the yeast C. viswanathii a $25 \%$ reduction in $\mu_{\max }$ was not observed at any of the adipic acid concentrations tested. This comparison, at $25 \%$ reduction in $\mu_{\max }$, indicates that yeasts tolerate roughly 10-100 times higher concentrations of adipic acid than bacteria. A $50 \%$ reduction in $\mu_{\max }$ was not observed in any yeast or A. niger, whereas a $75 \%$ reduction was observed in all three bacterial strains, even at adipic acid concentrations below $150 \mathrm{mM}$.

\section{Bacteria are more affected by the degree of dissociation of adipic acid than yeasts and A. niger}

All the microorganisms included in this study were more affected by adipic acid at lower $\mathrm{pH}$, in other words, in the presence of a greater fraction of undissociated adipic acid, than at higher $\mathrm{pH}$ (less undissociated acid). The amount of undissociated adipic acid increased from negligible amounts at $\mathrm{pH} 7-0.5 \%$ at $\mathrm{pH} 6$. Although the difference in the amount of undissociated adipic acid was low, roughly 10-100 times higher total adipic acid concentration was required to reduce $\mu_{\max }$ of bacteria by $25 \%$ at $\mathrm{pH} 7$, compared to $\mathrm{pH}$ 6. When the $\mathrm{pH}$ was further decreased from $\mathrm{pH} 6$ to $\mathrm{pH} 5$, the amount of undissociated adipic acid increased from 0.5 to $13.8 \%$. Although the increase in undissociated adipic acid was greater for yeasts and $A$. niger compared with bacteria, only 1-4 times higher total adipic acid concentration was required to reduce $\mu_{\max }$ by $25 \%$ at $\mathrm{pH} 6$ compared to $\mathrm{pH}$ 5. Therefore, it can be concluded that bacteria are more affected by the presence of diffusible undissociated adipic acid than yeasts and $A$. niger.

\section{Discussion}

Due to the high global demand for adipic acid and the unsustainable petroleum based process currently used, biobased-production of adipic acid is one of the primary

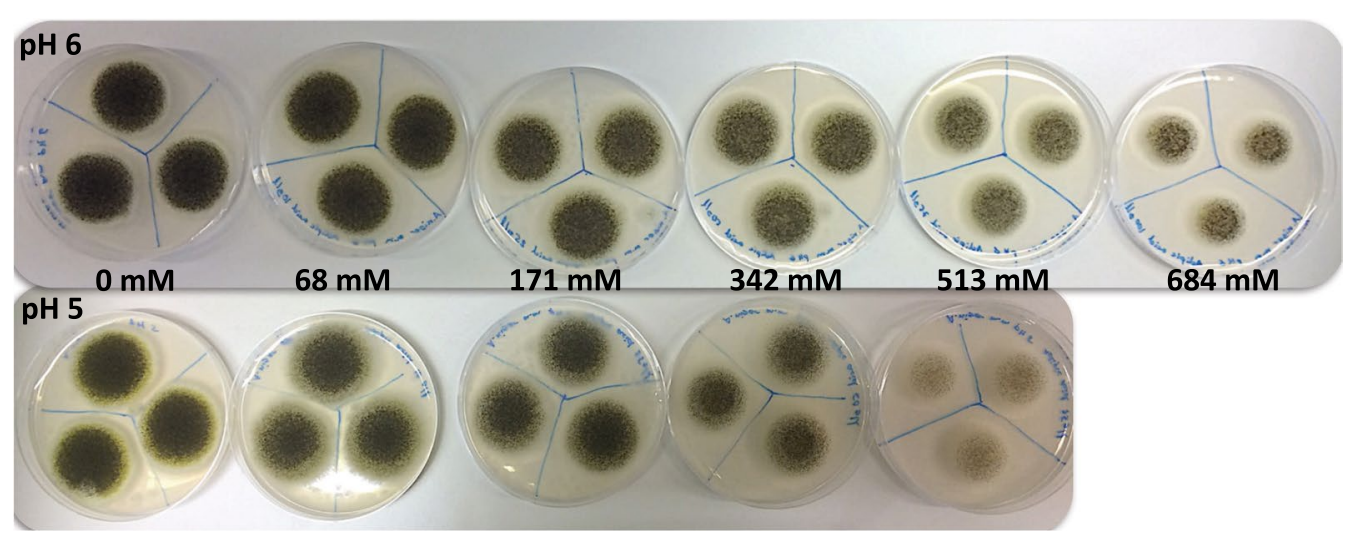

Fig. 6 Effect of adipic acid and pH on spore formation of A. niger. Agar plates with triplicate cultures of A. niger, 5 days after inoculation at pH 6 (above) and pH 5 (below) at various adipic acid concentrations. Due to solubility issue there is no plate at $684 \mathrm{mM}$ adipic acid for $\mathrm{pH} 5$ 


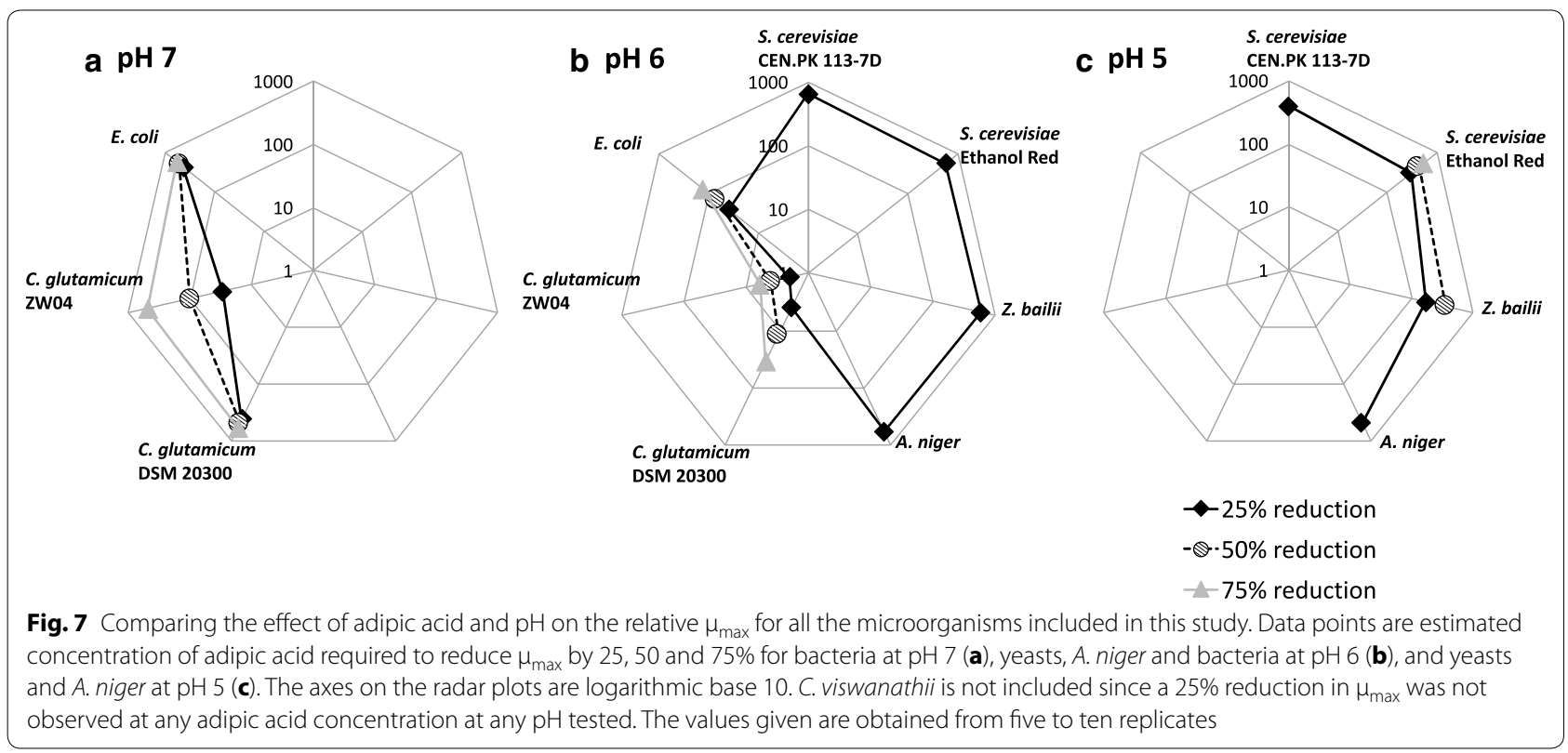

targets for platform chemicals in biorefineries. Establishing a microbial cell factory for adipic acid production from renewable sources is one of the options that can be considered $[8,9]$. Tolerance to adipic acid is a critical factor that should be considered when selecting a suitable host for biobased-production; however, to the best of our knowledge, no studies addressing this matter have yet been published. In the present study, we investigated the levels of tolerance of a range of microorganisms to adipic acid, from yeasts filamentous fungi and bacteria.

In the following sections the mode of entry of adipic acid is hypothesized to be mainly via passive diffusion of the undissociated form of adipic acid [18, 19]. It should be emphasized that in this study neither extra- nor intracellular concentrations of adipic acid was determined; therefore the following discussion aims to put forth hypotheses based on the observed differences in growth between the studied microorganisms in the presence of adipic acid. Hence, further experiments will be necessary to prove the actual mode of inflow and action of adipic acid on the cellular physiology leading to the effect we observed on the specific growth rate.

\section{Why do yeasts and $A$. niger have greater tolerance to adipic acid than bacteria?}

When comparing the tolerance levels exhibited by the investigated microorganisms at the same $\mathrm{pH}$, it was clear that yeasts and $A$. niger tolerated substantially higher concentrations of adipic acid than bacteria. There may be several reasons for these differences associated with fundamental physiological differences between these microorganisms. These differences are addressed and discussed below in terms of their potential influence in determining the level of tolerance to adipic acid.

The surface-to-volume ratio may affect the tolerance to adipic acid. This ratio increases with decreasing cell size, and will thus be greater for bacteria than for yeasts and A. niger. More acid can diffuse into smaller cells (i.e., bacteria), which may explain the better tolerance of yeasts and $A$. niger to the acid.

The membrane composition may also affect the rate of diffusion of the undissociated form of adipic acid through the membrane. Sphingolipids, which have been found to be present in the cell membranes of yeasts, have been shown to be important for tolerance to both acids [36, 39] and low $\mathrm{pH}$ [40]. Sterols, present in the membrane of eukaryotes but only found to be present in very few bacteria, are important in controlling the cell permeability [41]. Since there are no sphingolipids in bacterial cell membranes and sterols are not commonly found $[41,42]$, bacterial membranes are probably more permeable to undissociated adipic acid. Therefore, extracellular undissociated adipic acid can cross bacterial membranes at a higher rate than yeast cell membranes, thus causing higher detoxification demands. A potentially higher diffusion rate of the extracellular undissociated adipic acid will also increase the shift of the extracellular equilibrium between the different adipic acid forms towards the undissociated one, which then can diffuse over the membrane and continue to cause higher detoxification demands.

An additional factor potentially influencing the level of tolerance to adipic acid is associated with the presence of transporters for the active transport of specific 
molecules, possibly including the dissociated forms of adipic acid. No specific membrane transporters for adipic acid have been reported so far, although the citrate transporter CitP of Lactococcus lactis has been shown to have very broad substrate specificity including the ability to transport adipic acid intracellularly [43]. Despite of the lack of knowledge on specific adipic acid transporters, it could be hypothesized that adipic acid may be transported by other di- or tri-carboxylic acid transporters. In fact, these transporters have been reported in both yeast and bacteria [44-48]. Based on the studies published, it is difficult to conclude whether there are any relevant differences between the transporters in yeasts and bacteria that could explain the higher tolerance of yeasts to adipic acid. However, altering the substrate specificity of organic acid transporters or knocking out specific transporters of adipic acid could provide a strategy for increasing the tolerance to adipic acid.

Cell compartmentalization, which is typical in eukaryotic systems such as yeasts and filamentous fungi, may also play a role in determining the observed difference in tolerance. In bacteria, all macromolecules are found unprotected in the cytosol where also all the metabolic reactions take place. Using the tricarboxylic acid cycle (TCA cycle) as an example, any acid molecule able to inhibit the TCA cycle, entering a bacterial cell can directly interfere with the enzymes of the TCA cycle, since the TCA cycle takes place directly in the cytosol. In contrast, in order to exert an inhibitory effect on the TCA cycle in eukaryotic systems, the acid molecule must also pass through the mitochondrial membrane. Furthermore, the near-neutral $\mathrm{pH}$ of the cytosol leads to acid deprotonation, thereby hindering its further potential diffusion through the mitochondrial membrane. In addition, eukaryotic systems contain vacuoles which play a role in the homeostasis of several ions and also of the intracellular $\mathrm{pH}$ [49]. The vacuole lumen has been shown to have an acidic $\mathrm{pH}$ due to the action of vacuolar membrane ATPases. The acidic $\mathrm{pH}$ of the vacuole is also crucial for cellular functionality, as the proton gradient thus generated is used for other essential transport mechanisms across the vacuolar membrane [50]. The presence of vacuoles thus provides eukaryotes with a means of decreasing the concentration of cytosolic protons and in the case of adipic acid provides higher tolerance to protons from undissociated adipic acid.

The cytosolic $\mathrm{pH}$, which affects the form of adipic acid once it is in the intracellular environment, may also play a role in acid tolerance. The cytosolic $\mathrm{pH}$ of bacteria and yeasts included in this study is at optimal growth conditions approximately $7.5[15,51,52]$ and 7.0 [53] respectively. The amount of fully dissociated adipic acid at $\mathrm{pH}$ 7.0 and 7.5 is 97.5 and $99.2 \%$, respectively, resulting in slightly more of the protons released from undissociated adipic acid entering in bacteria than in yeast. Due to this difference, the concentration gradient, and hence the diffusion rate of undissociated adipic acid, is slightly higher in bacteria than yeast. The difference in $\mathrm{pH}$ means that the internal concentration of protons in yeasts is roughly three times higher than that in bacteria and thus, yeasts may be better adapted to acidic environments than bacteria. This could be one reason why yeasts can tolerate lower $\mathrm{pH}$ than bacteria and are better adapted to acid stress.

Under optimal conditions, ATP is generated for cell formation and maintenance. When cells encounter acid stress, there is an additional need for ATP by the cellular $\mathrm{H}^{+}$pumps to remove $\mathrm{H}^{+}$ions from the cytosol to maintain the intracellular $\mathrm{pH}$ at physiological values $[53,54]$. This additional need for ATP re-directs the ATP formed away from cell mass formation and possibly also maintenance. ATP is generated via respiration, by the complete oxidation of glucose to $\mathrm{CO}_{2}$, and/or via substrate-level phosphorylation (i.e. glycolysis), generating less oxidized products, such as ethanol in the case of S. cerevisiae and acetic acid in the case of $E$. coli. In some microorganisms ATP can be generated via a combination of respiration and substrate-level phosphorylation. In terms of the ATP generated per glucose molecule, respiration yields more ATP than substrate-level phosphorylation. As a result of the difference in ATP generation, microorganisms using respiration are more likely to generate enough ATP to cope with acid stress (assuming otherwise similar conditions).

The yeasts S. cerevisiae and Z. bailii are both Crabtreepositive and ATP is formed via both respiration and substrate-level phosphorylation. In the case of C. viswanathii, on the other hand, the predominant path of ATP generation is likely to be respiration [37]. The fact that $\mu_{\max }$ was reduced by roughly $30 \%$ when $C$. viswanathii was cultivated in a microplate, compared to a shake flask (data not shown) further supports this theory, since it is known that the microplate cultivations used in the present study result in slight oxygen limitation [31]. As there is no way to direct ATP production towards substratelevel phosphorylation, the rate of ATP production will probably decrease with decreasing oxygen availability.

Escherichia coli is able to respiro-ferment via mixed acid fermentation, generating ATP via the formation of acetic acid. However, if oxygen is available, respiration is preferred over substrate-level phosphorylation [55]. C. glutamicum is also able to use mixed acid fermentation for the metabolism of glucose, but under such conditions cell growth is arrested [56]. In the present study, $\mu_{\max }$ was decreased by roughly $50 \%$ in both C. glutamicum strains when cultivated in microplates compared to shake flasks 
(data not shown). This may indicate that the metabolism and hence the route for ATP formation shifted towards a higher flux via substrate-level phosphorylation, and hence less ATP was formed when cells were cultivated under slight oxygen limitation in the microplate. Although both $S$. cerevisiae and $Z$. bailii prefer the less ATP-yielding substrate-level phosphorylation over respiration, these strains were less affected by adipic acid, in terms of both relative $\mu_{\max }$ and final OD when grown on glucose, compared to bacteria, indicating that ATP generation is not the main reason for the higher tolerance of the yeasts $S$ cerevisiae and $Z$. bailii to adipic acid than that exhibited by bacteria. The inflow of adipic acid (by passive diffusion or other means) is probably higher in bacteria than yeasts, resulting in a greater reduction in $\mu_{\max }$ and less cell mass being formed. The observation that bacteria were more affected by an increase in undissociated adipic acid than yeasts and $A$. niger further supports the hypothesis of a higher inflow of adipic acid in bacteria than in yeasts and $A$. niger.

When the metabolism of $S$. cerevisiae changed from respiro-fermentation to full respiration the lag phase between the two growth phases increased with increasing adipic acid concentration. During this lag phase, as glucose is depleted, stress responses are induced, and gene expression is reprogrammed such that the genes controlling fermentative metabolism are down-regulated and those controlling respiratory metabolism are upregulated $[57,58]$. In addition to the stress to which the cells are exposed due to glucose starvation, cells cultivated in the presence of adipic acid are subjected to an additional, acid, stress, requiring detoxification. This requires ATP, probably diverting ATP from reprogramming of the metabolism, thus leading to an extension of the lag phase. After the diauxic shift, $\mu_{\max }$ of $S$. cerevisiae was strongly affected by increasing adipic acid concentration. Assuming there are no major changes in membrane composition or the transporters present, the inflow of adipic acid should be unaffected. The interference of enzymes in the TCA cycle by adipic acid may explain why respiration was more affected, despite the higher ATP yield. These enzymes have specificity for diacids, including succinic acid, which is two carbons shorter than adipic acid. The dicarboxylic acid, malonic acid, has previously been reported to inhibit oxidation of both succinate and oxaloacetate in the TCA cycle [59]. The hypothesis that adipic acid interferes with the TCA cycle would also provide an additional explanation of why bacteria were more affected than yeasts and $A$. niger, since the respiratory metabolism in bacteria takes place in the inner membrane and is therefore unprotected, compared to yeast and $A$. niger, where it takes place inside the mitochondria.

As discussed above, there are several differences between yeasts, $A$. niger and bacteria, in terms of their overall physiology and their paths of ATP generation. From the results obtained in this study it cannot be concluded which of these factors has the greatest effect on tolerance to adipic, and the differences in tolerance are most likely due to a combination of all the physiological and metabolic differences discussed above.

\section{Adipic acid tolerance in solid versus liquid media}

Due to limitations inherent to the instrument used to monitor biomass growth, the methods for screening the effect of adipic acid on microbial growth differed between yeast and bacteria, which were studied in liquid media, compared with the filamentous fungus $A$. niger which was studied using a solid agar-media. As different methodologies was applied the level of tolerance to adipic acid can not be directly compared. Nevertheless, we believe that the results of the present study are representative of the level of tolerance of $A$. niger to adipic acid. Further studies of $A$. niger submerged cultures will be necessary to better quantify the level of tolerance of $A$. niger to adipic acid.

\section{Lysine overproduction may affect tolerance to adipic acid}

The lysine overproducing strain, C. glutamicum ZW04, was less tolerant to adipic acid at both $\mathrm{pH} 6$ and $\mathrm{pH} 7$, than its parental wild type strain C. glutamicum DSM 20300. The difference between these two strains lies in three mutations in the lysine-producing pathway, namely: lys (T311I), hom (V59A) and pycA (P458S) [60]. These modifications increase the flux towards lysine at the expense of the TCA flux [29, 60] (Fig. 8). In addition, the production of lysine requires NADPH, which can be balanced by an increased flux through the pentose phosphate pathway [61]. The reduced flux in the TCA cycle, together with an increase in flux through the pentose phosphate pathway, is likely to lead to the generation of less ATP and, consequently, this strain would be less efficient than the wild type in reactions requiring ATP such as pumping out adipate and protons.

\section{Suitable host for future adipic acid production}

In order for the biobased production of adipic acid to be economically feasible, the microbial host must tolerate acid titres of 50-100 g/L adipic acid [14, 15] (corresponding to $340-680 \mathrm{mM}$ ). At these adipic acid concentrations, all bacteria included in this study lost their ability to grow, even at $\mathrm{pH} 7$ and therefore, they appear not to be suitable candidates for biobased adipic acid production. However, if the titres could be reduced, and the process run at neutral $\mathrm{pH}$, without having too severe impact on the economy of the process, a bacterial host could serve as a possible adipic acid producer.

Aspergillus niger and all yeasts investigated, apart from Ethanol Red, were able to grow on glucose in presence of 


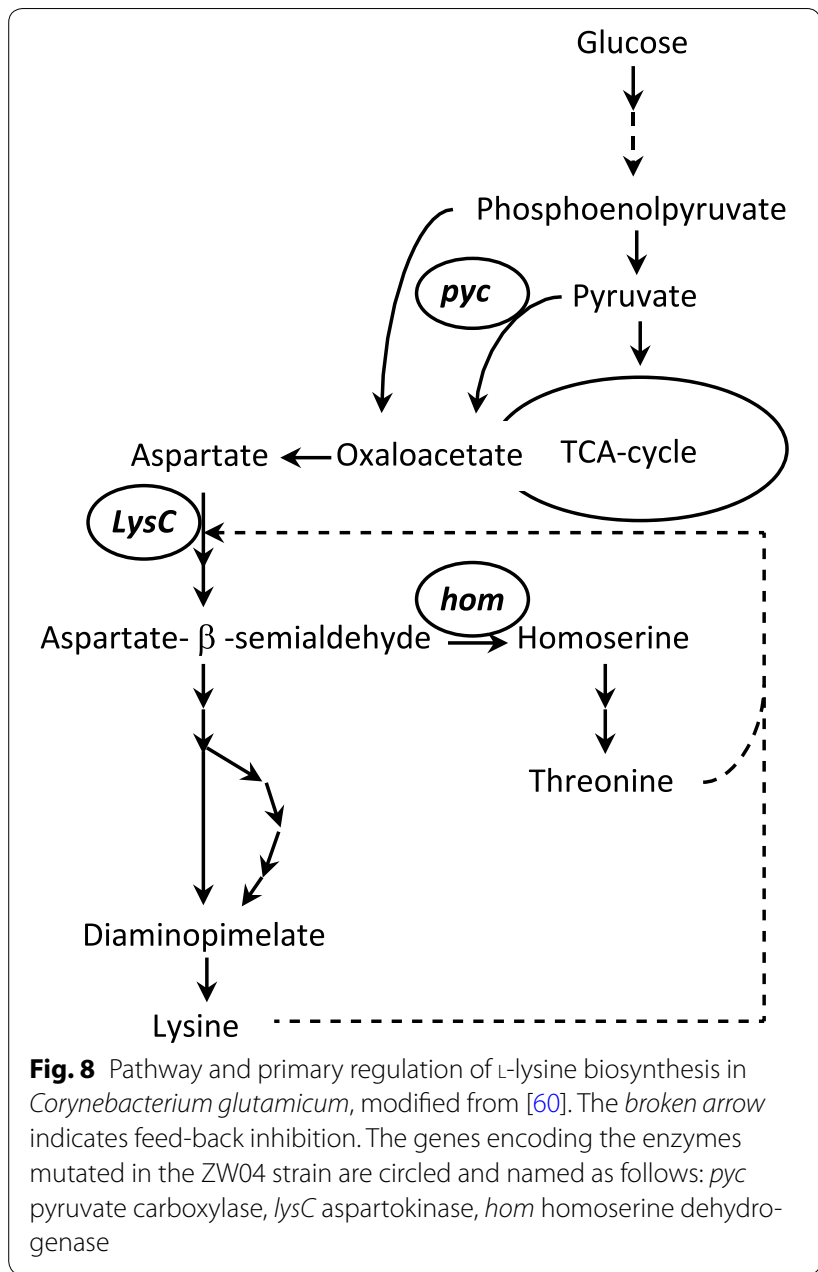

$384 \mathrm{mM}$ and $650 \mathrm{mM}$ adipic acid at $\mathrm{pH}$ 5. C. viswanathii was the yeast species least affected by adipic acid, and its growth was almost unaffected, even at the highest adipic acid concentration $(650 \mathrm{mM})$, also at $\mathrm{pH} 5$. Tolerance to adipic acid at low $\mathrm{pH}$ is an additional advantage due to the reduced cost of downstream processing [16]. Plausible explanations why $C$. viswanathii is more tolerant to adipic acid than the other yeast species included in this study may be associated with membrane composition and functionality. This species has been reported to grow on fatty acids and alkanes as sole carbon source $[7,33]$.

Candida viswanathii may thus have evolved a membrane with low permeability for fatty acids, which could also mean it is less permeable to adipic acid, and hence more tolerant. Engineering C. viswanathii to a host that can produce adipic acid requires knowledge about its genome, and a molecular toolbox to make the necessary genetic alterations. Although $C$. viswanathii has been much less studied than, for instance, the model yeast $S$. cerevisiae, its genome is available [62], and there are several reports on genetic modifications indicating molecular tools are available [63-66]. However, it may be suggested that $C$. viswanathii has primarily respiratory metabolism, as has been proposed for the closely related Candida tropicalis [37], thus anaerobic fermentation cannot be utilized, and the overall cost of supplying the reactor with oxygen will increase. This cost could be avoided by using the well characterized yeast $S$. cerevisiae as a potential host, since it is able to ferment under anaerobic conditions, and showed high tolerance to adipic acid, although the industrial strain Ethanol Red was sensitive to adipic acid at concentrations of $384 \mathrm{mM}$ and above.

\section{Conclusions}

In this screening study, yeasts and $A$. niger were found to have substantially higher tolerance to the total adipic acid concentration than the investigated bacterial strains. Yeasts and $A$. niger were also found to tolerate a greater increase in the membrane-diffusible form of undissociated adipic acid than bacteria, due to a decrease in the $\mathrm{pH}$. The yeast species $C$. viswanathii exhibited the highest tolerance to adipic acid and was almost unaffected by the presence of even the highest adipic acid concentration tested $(650 \mathrm{mM})$. Changing the $\mathrm{pH}$ had no effect on C. viswanathi level of tolerance, which is beneficial in an industrial setting due to the reduced cost of downstream processing at lower $\mathrm{pH}$.

Possible reasons why bacteria were more affected by adipic acid than yeasts and $A$. niger were discussed. Overall, there are several plausible explanations including differences in surface-to-volume ratio, membrane composition, membrane transporters, cytosolic $\mathrm{pH}$, cell compartmentalization and ATP generation. The difference observed in the tolerance of bacteria and yeasts is probably not due to only one of these parameters, but rather a combination of them.

It was also noted that respiratory growth of $S$. cerevisiae was more affected than respiro-fermentative growth with increasing adipic acid concentration. It was suggested that the reason for this could be inhibition of the enzymes in the TCA cycle by adipic acid.

\section{Additional file}

Additional file 1. Growth curves from microtiter plate cultivations. The data contains growth curves for all microorganisms include in the study cultivated in microtiter plates.

\section{Authors' contributions}

EK designed and performed the experiment, analysed the data and wrote the manuscript. VM and LO participated in the experimental design, helped in analysing the data and helped in writing the manuscript. All authors read and approved the final manuscript. 


\section{Author details}

${ }^{1}$ Department of Biology and Biological Engineering, Division of Industrial Biotechnology, Chalmers University of Technology, Gothenburg, Sweden. ${ }^{2}$ Sacco S.r.l., Cadorago, CO, Italy.

\section{Acknowledgements}

The authors would like to thank Professor Peter Ruhdal Jensen (The National Food Institute, Technical University of Denmark, Kongens, Lyngby, Denmark) for his kind gift of the lysine-overproducing strain C. glutamicum ZW04.

\section{Competing interests}

The authors declare that they have no competing interests.

\section{Availability of data and materials}

The datasets used and analysed during the study are available from the corresponding author on reasonable request.

\section{Funding}

This research was funded by The Swedish Research Council Formas (no. 201378) under the programme for strong research environments in bioeconomy.

Received: 4 November 2016 Accepted: 21 January 2017

Published online: 01 February 2017

\section{References}

1. Babu T, Yun EJ, Kim S, Kim DH, Liu KH, Kim SR, et al. Engineering Escherichia coli for the production of adipic acid through the reversed $\beta$-oxidation pathway. Process Biochem. 2015;50(12):2066-71.

2. Cheong S, Clomburg JM, Gonzalez R. Energy- and carbon-efficient synthesis of functionalized small molecules in bacteria using non-decarboxylative Claisen condensation reactions. Nat Biotechnol. 2016;34(5):556-5563.

3. Clomburg JM, Blankschien MD, Vick JE, Chou A, Kim S, Gonzalez R. Integrated engineering of $\beta$-oxidation reversal and $\omega$-oxidation pathways for the synthesis of medium chain $\omega$-functionalized carboxylic acids. Metab Eng. 2015;28:202-12.

4. Deng Y, Mao Y. Production of adipic acid by the native-occurring pathway in Thermobifida fusca B6. J Appl Microbiol. 2015;119:1057-63.

5. Parthasarathy A, Pierik AJ, Kahnt J, Zelder O, Buckel W. Substrate specificity of 2-hydroxyglutaryl-CoA dehydratase from Clostridium symbiosum: toward a bio-based production of adipic acid. Biochemistry. 2011;50(17):3540-50.

6. Turk SCHJ, Kloosterman WP, Ninaber DK, Kolen KPA, Knutova J, Suir E, et al. Metabolic engineering towards sustainable production of nylon-6. ACS Synth Biol. 2015;5:65-73.

7. Beardslee T, Picataggio S. Bio-based adipic acid from renewable oils. Lipid Technol. 2012;24(10):223-5.

8. Van Ree R, De Jong E, Kwant K. Bio-based chemicals value added products from biorefineries. Report prepared on behalf of IEA bioenergytask 42 biorefinery; 2011.

9. Bart JCJ, Cavallaro S. Transiting from adipic acid to bioadipic acid. Part II. Biosynthetic pathways. Ind Eng Chem Res. 2015;54(2):567-76.

10. Polen T, Spelberg M, Bott M. Toward biotechnological production of adipic acid and precursors from biorenewables. J Biotechnol. 2013;167(2):75-84.

11. Buijs NA, Siewers V, Nielsen J. Advanced biofuel production by the yeast Saccharomyces cerevisiae. Curr Opin Chem Biol. 2013;17(3):480-8.

12. Ikeda M. Amino acid production processes. Adv Biochem Eng Biotechnol. 2003;79:1-35.

13. Max B, Salgado JM, Rodríguez N, Cortés S, Converti A, Domínguez JM. Biotechnological production of citric acid. Braz J Microbiol. 2010;41(4):862-75.

14. Wang J, Lin M, Xu M, Yang S-T, Wang J, Lowrie WG, et al. Anaerobic fermentation for production of carboxylic acids as bulk chemicals from renewable biomass. Adv Biochem Eng Biotechnol. 2016;56:323-62.

15. Warnecke T, Gill RT. Organic acid toxicity, tolerance, and production in Escherichia coli biorefining applications. Microb Cell Fact. 2005:4:25.
16. Tsuge Y, Kawaguchi H, Sasaki K, Kondo A. Engineering cell factories for producing building block chemicals for bio-polymer synthesis. Microb Cell Fact. 2016;15(1):19

17. Warth A. Transport of benzoic and propanoic acids by Zygosaccharomyces bailii. J Gen Microbiol. 1989;1989:1383-90.

18. Verduyn C, Postma E, Scheffers WA, Van Dijken JP. Effect of benzoic acid on metabolic fluxes in yeasts: a continuous-culture study on the regulation of respiration and alcoholic fermentation. Yeast. 1992;8(7):501-17.

19. Lindén T, Peetre J, Hahn-Hägerdal B. Isolation and characterization of acetic acid-tolerant galactose-fermenting strains of Saccharomyces cerevisiae from a spent sulfite liquor fermentation plant. Appl Environ Microbiol. 1992;58(5):1661-9.

20. Yu J-L, Xia X-X, Zhong J-J, Qian Z-G. Direct biosynthesis of adipic acid from a synthetic pathway in recombinant Escherichia coli. Biotechnol Bioeng. 2014;111:2580-6.

21. Jensen KF. The Escherichia coli K-12'wild types'W3110 and MG1655 have an rph frameshift mutation that leads to pyrimidine starvation due to low pyrE expression levels. J Bacteriol. 1993;175(11):3401-7.

22. Yamada K, Komagata K. Taxonomic studies on coryneform bacteria dna base composition of coryneform bacteria. J Gen Appl Microbiol. 1970;16:215-24.

23. Wang Z, Moslehi-Jenabian S, Solem C, Jensen PR. Increased expression of pyruvate carboxylase and biotin protein ligase increases lysine production in a biotin prototrophic Corynebacterium glutamicum strain. Eng Life Sci. 2015;15(1):73-82

24. Entian K-D, Kötter P. 25 yeast genetic strain and plasmid collections. Methods Microbiol. 2007;36:629-66.

25. Teranishi Y, Tanaka A, Osumi M, Fukui S. Catalase activities of hydrocarbon-utilizing Candida yeasts. Agric Biol Chem. 1974;38(6):1213-20.

26. Andersen MR, Salazar MP, Schaap PJ, van de Vondervoort PJI, Culley D, Thykaer J, et al. Comparative genomics of citric-acid-producing Aspergillus niger ATCC 1015 versus enzyme-producing CBS 513.88. Genome Res. 2011;21(6):885-97.

27. Verduyn C, Postma E, Scheffers WA, van Dijken JP. Effect of benzoic acid on metabolic fluxes in yeasts. Yeast. 1992;1992(8):501-17.

28. Kind S, Jeong WK, Schröder H, Wittmann C. Systems-wide metabolic pathway engineering in Corynebacterium glutamicum for bio-based production of diaminopentane. Metab Eng. 2010;12(4):341-51.

29. Vallino JJ, Stephanopoulos G. Metabolic flux distributions in Corynebacterium glutamicum during growth and lysine overproduction. Biotechnol Bioeng. 1993;41:633-46.

30. de Vries RP, Burgers K, van de Vondervoort PJI, Frisvad JC, Samson RA, Visser J. A new black Aspergillus species, A. vadensis, is a promising host for homologous and heterologous protein production. Appl Environ Microbiol. 2004;70(7):3954-9.

31. Warringer J, Blomberg A. Automated screening in environmental arrays allows analysis of quantitative phenotypic profiles in Saccharomyces cerevisiae. Yeast. 2003;20(1):53-67.

32. Stratford M, Steels H, Nebe-von-Caron G, Novodvorska M, Hayer K, Archer DB. Extreme resistance to weak-acid preservatives in the spoilage yeast Zygosaccharomyces bailii. Int J Food Microbiol. 2013;166(1):126-34.

33. De Almeida AF, Taulk-Tornisielo SM, Carmona EC. Influence of carbon and nitrogen sources on lipase production by a newly isolated Candida viswanathii strain. Ann Microbiol. 2013;63(4):1225-34.

34. Picataggio S, Beardslee T. Biological methods for preparing adipic acid. US; US 2013/0157343 A1, 2013.

35. Rodrigues F, Côrte-Real M, Leao C, Van Dijken JP, Pronk JT. Oxygen requirements of the food spoilage yeast Zygosaccharomyces bailii in synthetic and complex media. Appl Environ Microbiol. 2001;67(5):2123-8.

36. Lindberg L, Santos AXS, Riezman H, Olsson L, Bettiga M. Lipidomic profiling of Saccharomyces cerevisiae and Zygosaccharomyces bailii reveals critical changes in lipid composition in response to acetic acid stress. PLOS ONE. 2013;8(9):1-12.

37. Mishra P, Park G-Y, Lakshmanan M, Lee H-S, Lee H, Chang MW, et al. Genome-scale metabolic modeling and in silico analysis of lipid accumulating yeast Candida tropicalis for dicarboxylic acid production. Biotechno Bioeng. 2016;9999:1-12.

38. Latimer P. Light scattering vs. microscopy for measuring average cell size and shape. Biophys J. 1979;27(1):117-26. 
39. Lindahl L, Genheden S, Eriksson LA, Olsson L, Bettiga M. Sphingolipids contribute to acetic acid resistance in Zygosaccharomyces bailii. Biotechnol Bioeng. 2016;113(4):744-53.

40. van der Rest ME, Kamminga AH, Nakano A, Anraku Y, Poolman B, Konings WN. The plasma membrane of Saccharomyces cerevisiae: structure, function, and biogenesis. Microbiol Rev. 1995;59(2):304-22.

41. Volkman JK. Mini-review—sterols in microorganisms. Appl Microbiol Biotechnol. 2003;60:495-506.

42. Silhavy TJ, Kahne D, Walker S. The bacterial cell envelope. Cold Spring Harb Perspect Biol. 2010;2(5):a000414.

43. Pudlik AM, Lolkema JS. Substrate specificity of the citrate transporter CitP of Lactococcus lactis. J Bacteriol. 2012;194(14):3627-35.

44. Ramos J, Sychrová H, Kschischo M. Yeast membrane transport. Berlin: Springer; 2016. p. 11-31.

45. Aliverdieva DA, Mamaev DV, Bondarenko DI, Sholtz KF. Properties of yeast Saccharomyces cerevisiae plasma membrane dicarboxylate transporter. Biochem Biokhimiia. 2006;71(10):1161-9.

46. Casal M, Paiva S, Queirós O, Soares-Silva I. Transport of carboxylic acids in yeasts. FEMS Microbiol Rev. 2008;32(6):974-94.

47. Youn J-W, Jolkver E, Krämer R, Marin K, Wendisch VF. Identification and characterization of the dicarboxylate uptake system DccT in Corynebacterium glutamicum. J Bacteriol. 2008;190(19):6458-66.

48. Jamalzadeh E, Verheijen PJ, Heijnen JJ, van Gulik WM. pH-dependent uptake of fumaric acid in saccharomyces cerevisiae under anaerobic conditions. Appl Environ Microbiol. 2011;78:705-16.

49. Klionsky DJ, Herman PK, Emr SD. The fungal vacuole: composition, function, and biogenesis. Microbiol Rev. 1990;54(3):266-92.

50. Anraku Y, Hirata R, Wada Y, Ohya Y. Molecular genetics of the yeast vacuolar H(+)-ATPase. J Exp Biol. 1992;172:67-81.

51. Follmann M, Ochrombel I, Krämer R, Trötschel C, Poetsch A, Rückert C, et al. Functional genomics of $\mathrm{pH}$ homeostasis in Corynebacterium glutamicum revealed novel links between $\mathrm{pH}$ response, oxidative stress, iron homeostasis and methionine synthesis. BMC Genom. 2009:10:621.

52. Wilks JC, Slonczewski JL. pH of the cytoplasm and periplasm of Escherichia coli: rapid measurement by green fluorescent protein fluorimetry. J Bacteriol. 2007;189(15):5601-7.

53. Orij R, Brul S, Smits GJ. Intracellular $\mathrm{pH}$ is a tightly controlled signal in yeast. Biochim Biophys Acta Gen Subj. 2011;1810(10):933-44.

54. Liu Y, Tang H, Lin Z, Xu P. Mechanisms of acid tolerance in bacteria and prospects in biotechnology and bioremediation. Biotechnol Adv. 2015;33(7):1484-92
55. Förster $\mathrm{AH}$, Gescher J. Metabolic engineering of Escherichia coli for production of mixed-acid fermentation end products. Front Bioeng Biotechnol. 2014;2:16.

56. Okino S, Noburyu R, Suda M, Jojima T, Inui M, Yukawa H. An efficient succinic acid production process in a metabolically engineered Corynebacterium glutamicum strain. Appl Microbiol Biotechnol. 2008;81(3):459-64.

57. Soontorngun N. Reprogramming of nonfermentative metabolism by stress-responsive transcription factors in the yeast Saccharomyces cerevisiae Curr Genet. 2016:1-7. doi:10.1007/s00294-016-0609-z

58. DeRisi JL, lyer VR, Brown PO. Exploring the metabolic and genetic control of gene expression on a genomic scale. Science (80-). 1997;278(5338):680 LP-6 LP.

59. Pardeet $A B$, Potter VR. Malonate inhibition of oxidations in the Krebs tricarboxylic acid cycle. J Biol Chem. 1949;179:241-50.

60. Ohnishi J, Mitsuhashi S, Hayashi M, Ando S, Yokoi H, Ochiai K, et al. A novel methodology employing Corynebacterium glutamicum genome information to generate a new L-lysine-producing mutant. Appl Microbiol Biotechnol. 2002:58(2):217-23.

61. Bommareddy RR, Chen Z, Rappert S, Zeng A-P. A de novo NADPH generation pathway for improving lysine production of Corynebacterium glutamicum by rational design of the coenzyme specificity of glyceraldehyde 3-phosphate dehydrogenase. Metab Eng. 2014;25:30-7.

62. Butler G, Rasmussen MD, Lin MF, Santos MAS, Sakthikumar S, Munro CA, et al. Evolution of pathogenicity and sexual reproduction in eight Candida genomes. Nature. 2009;459(7247):657-62.

63. Craft DL, et al. Identification and characterization of the CYP52 Family of Candida tropicalis ATCC 20336, important for the conversion of fatty acids and alkanes to a, $\omega$-dicarboxylic acids. Appl Environ Microbiol. 2003:69:5983-91.

64. Picataggio S, Deanda K, Mielenz J. Determination of Candida tropicalis acyl coenzyme A oxidase isozyme function by sequential gene disruption. Mol Cell Biol. 1991;11(9):4333-9.

65. Picataggio S, Rohrer T, Deanda K, Lanning D, Reynolds R, Mielenz J, et al. Metabolic engineering of Candida tropicalis for the production of longchain dicarboxylic acids. Nat Biotechnol. 1992;10(8):894-8.

66. Haas LO, Cregg JM, Gleeson MA. Development of an integrative DNA transformation system for the yeast Candida tropicalis. J Bacteriol. 1990;172(8):4571-7.

\section{Submit your next manuscript to BioMed Central and we will help you at every step:}

- We accept pre-submission inquiries

- Our selector tool helps you to find the most relevant journal

- We provide round the clock customer support

- Convenient online submission

- Thorough peer review

- Inclusion in PubMed and all major indexing services

- Maximum visibility for your research

Submit your manuscript at www.biomedcentral com/submit
BioMed Central 